\title{
Heart valve tissue engineering : how far is the bedside from the bench?
}

\section{Sanz-Garcia, Andres}

2015-09-24

Sanz-Garcia , A , Oliver-De-La-Cruz , J Mirabet , V , Gandia , C , Villagrasa , A, Sodupe , E \& Escobedo-Lucea , C 2015 , ' Heart valve tissue engineering : how far is the bedside from the bench? ' , Expert reviews in molecular medicine , vol. 17 , 16 . https://doi.org/10.1017/erm.2015.15

http://hdl.handle.net/10138/159359

https://doi.org/10.1017/erm.2015.15

unspecified

acceptedVersion

Downloaded from Helda, University of Helsinki institutional repository.

This is an electronic reprint of the original article.

This reprint may differ from the original in pagination and typographic detail.

Please cite the original version. 


\title{
Heart valve tissue engineering: How far is the
}

\section{bediside from the bench?}

\author{
ANDRES SANZ-GARCIA ${ }^{1,2 \dagger}$, JORGE OLIVER-DE-LA-CRUZ ${ }^{3 \dagger}$, VICENTE MIRABET $^{4}$, \\ CAROLINA GANDÍA ${ }^{1}$, ALEJANDRO VILLAGRASA ${ }^{5}$, ENRIQUE SODUPE ${ }^{6}$, AND CARMEN \\ ESCOBEDO-LUCEA ${ }^{1,2^{*}}$ \\ ${ }^{1}$ Division of Pharmaceutical Biosciences, Faculty of Pharmacy, University of Helsinki, 00014 Viikinkaari 5 E, \\ Helsinki, Finland. ${ }^{2}$ Institute of Advanced Biomedical Engineering and Science. Tokyo Women's Medical \\ University. 8-1 Kawada-Cho, 162-8666, Shinjuku-Ku, Tokyo, Japan. ${ }^{3}$ International Clinical Research Center, \\ Integrated Center of Cellular Therapy and Regenerative Medicine, St. Anne's University Hospital, Brno, \\ Czech Republic. ${ }^{4}$ Hospital Fundación Jimenez Diaz, IIS-FJD, 28040 Madrid. Spain. ${ }^{5}$ Faculty of Biology, \\ University of Valencia. 46100 Av. Dr. Moliner 50, Burjassot, Spain. ${ }^{6}$ EDMANS Group, University of La Rioja. \\ 26004 C/ Luis de Ulloa, 20, Logrono, Spain.
}

Heart disease, including valve pathologies, is the leading cause of death worldwide. Despite the progress made thanks to improving transplantation techniques, a perfect valve substitute has not yet been developed: once a diseased valve is replaced with current technologies, the newly implanted valve still needs to be changed some time in the future. This situation is particularly dramatic in the case of children and young adults, due to the necessity of valve growth during the patient's life. Our review focuses on the current status of heart valve therapy and the challenges that must be solved in the development of new approaches based on tissue engineering. Scientists and physicians have proposed tissue-engineered heart valves (TEHVs) as the most promising solution for heart valve replacement, especially given that they can help to avoid thrombosis, structural deterioration, and xenoinfections. Lastly, TEHVs might also serve as a model for studying human valve development and pathologies.

* Corresponding author: carmen.escobedo-lucea@helsinki.fi

\section{Introduction}

Cardiovascular diseases, including severe cardiac valve disorders, are the leading global cause of disability and death, causing more than 17.5 million deaths a year (Ref. 1); the prevalence of valvular heart disease in the United States of America (USA) is estimated at more than 5 million people. Moreover, aortic valve disease, which affects $2.5 \%$ of the US adult population to some extent, is responsible for more than 25,000 deaths each year (Ref. 2). Also, 3\% of sudden deaths in the European Union (EU) are caused by cardiac valve defects. Over the preceding decades valvular heart diseases were not considered a major public health problem. However, Nkomo et al. (Ref. 3) demonstrated in 2006 that the high prevalence of these disorders, together with their boost with

${ }^{\dagger}$ These authors contributed equally to this work. ageing, indicated the burden of these conditions would only likely increase in the future.

The advent of organ transplantation has brought about the greatest progress in cardiac valve disease treatment so far, however, the number of patients that need heart valve replacements is rising by an average of $5 \%$ per year (Ref. 4 ). This number is likely to triple over the next five decades due to the continuously increasing aging of the population in developed countries (Ref. 5). According to the Global Alliance in Transplantation, the USA is currently the world's leader in heart valve replacements, reaching 95,000 cases per year (Ref. 6 ) but this is not an exception. By the year 2020, $20.2 \%$ of EU population will be older than 65 . The growing pool of older people living in the area with age related heart valve disorders will continue to boost demand for heart valve repair and replacement procedures. These medical procedures, 
Expert Reviews in Molecular Medicine

only in EU countries, generated $\$ 827.5$ million expenses in 2010, and the estimate for 2015 is to reach $\$ 1,375.3$ million (Ref. 7).

Even more dramatic is the case of children and young adults where cardiac valve defects represent approximately $30 \%$ of all congenital cardiovascular malformations. Only in the USA, the incidence is estimated at $1-2 / 1,000$ births, and globally is around 8/1,000 births (Ref. 8,9). Congenital heart defects are relatively common and serious malformations having significant impact on morbidity, mortality, and healthcare costs. Homografts are used for their long durability in these patients but they show a higher immunological response compared to adults (Ref. 10). Moreover post-surgical calcification and the ultimate destruction of the valve replacement always occur more frequently in children and young adults than in old patients. In addition, the durability of the homografts in this case is also limited because of their inability to grow with concomitant growth of child organism. Consequently, the need for reoperation is higher in younger patients (O'Brien, 2001 \#898;Rajani, 1998 $\# 897\}$. Further efforts focused on paediatric recipients of cardiac valves are required.

Although organ replacement saves many lives the need for more donors, together with the collateral problems caused after transplantation, encourage the search for new alternatives (Ref. 11, 12). Cardiac valve replacement is not an exception to the rule and several problems have to be solved: the administration of lifelong immunosuppressive drugs, poor durability and resulting short lifespan of the mechanical prostheses, structural degradation of the biological valve replacement, risk of rejection, and the risk of zoonosis from xenotransplants. Even with the significant innovations currently reached, a perfect valve substitute has still not yet been developed (Ref. 11), and approaches based on tissue engineering (TE) are now being considered for developing artificial heart valves (Ref. 13, 14).

Tissue-engineered heart valves (TEHVs) have the potential to become the best solution for treating valvular heart diseases due to their nonthrombogenicity, decreased risk of infections and low structural deterioration over time (Ref. 13). There are two crucial challenges derived from three major components (cells, scaffolds and signalling molecules) in TE field; the former is the selection of potential candidate cell types and their related issues concerning ethics, safety, and effectiveness. The latter is the design of appropriate scaffolds that let for cell growth and differentiation as well as host tissue integration.

In this review we evaluate the current treatment strategies for valvular heart disease and their limitations with a view to provide valuable information in selecting the best approach for heart valve tissue engineering (HVTE), the challenges that HVTE faces today and the current status of the research in the field. This review focuses on the aortic valve due to the fact that aortic diseases have the poorest prognosis, even the higher incidence of mitral valve diseases in the population (Ref. 15). However, research on pulmonary valve is also taken into account since pulmonary autograft represents a proof of principle for clinical effectiveness of TEHVs (Ref. 16, 17).

\section{Understanding of heart valve biology}

\subsection{Substructural elements}

Mammalian hearts comprise four heart valves: pulmonary, aortic, mitral, and tricuspid, whose primary function is to maintain a unidirectional blood flow during the cardiac cycle. We focus in the first two types, which are shown in Figure 1a and $1 \mathrm{~b}$, but especially our main interest is the aortic valve. Pulmonary and aortic valves, also called semilunar valves, are commonly affected by pathological processes, but with distinct mechanisms of failure (Ref. 18) that we will treat later. Both share similar structure containing three semicircular leaflets, or cusps, joined to a fibrous annulus called the root. According to Stradins et al. (Ref. 19), aortic and pulmonary valve tissues have similar mechanical characteristics and composition, but exhibit slight differences in their layer density and thickness. The cross-sectional structure of the leaflets is divided into three layers, namely the ventricularis, spongiosa, and fibrosa (Ref. 12) whose structure and composition are detailed in the cross-sectional diagram in Figure 2. These layers are dynamic tissues with complex structure mainly composed of valvular interstitial cells (VICs) and endothelial cells (VECs) combined with extracellular matrix (ECM). This make them capable of remodelling themselves in response to the changes generated by local forces (Ref. 20). 
a

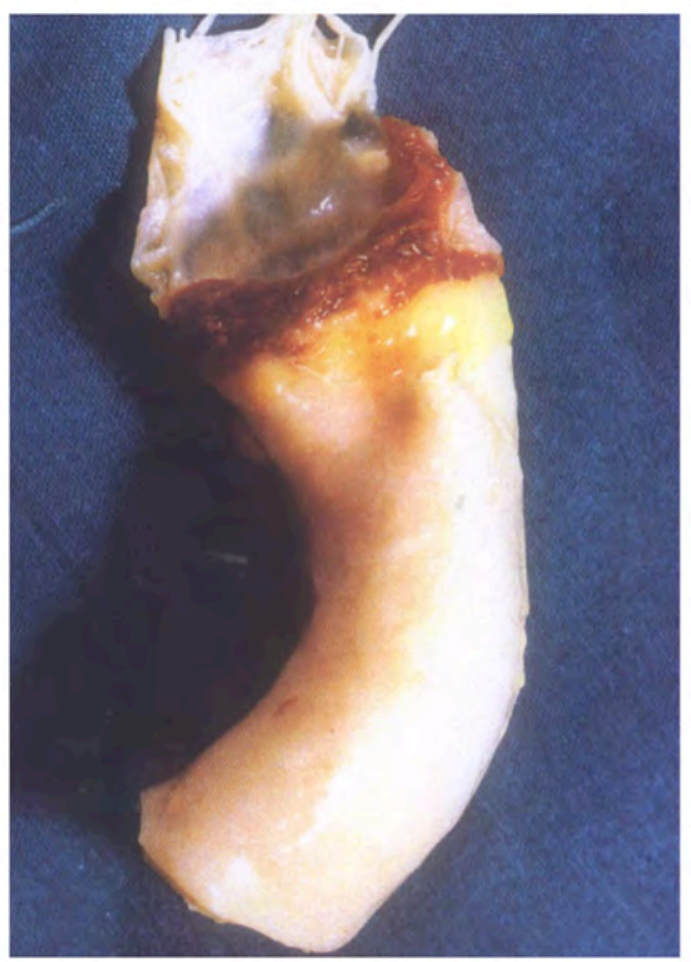

b

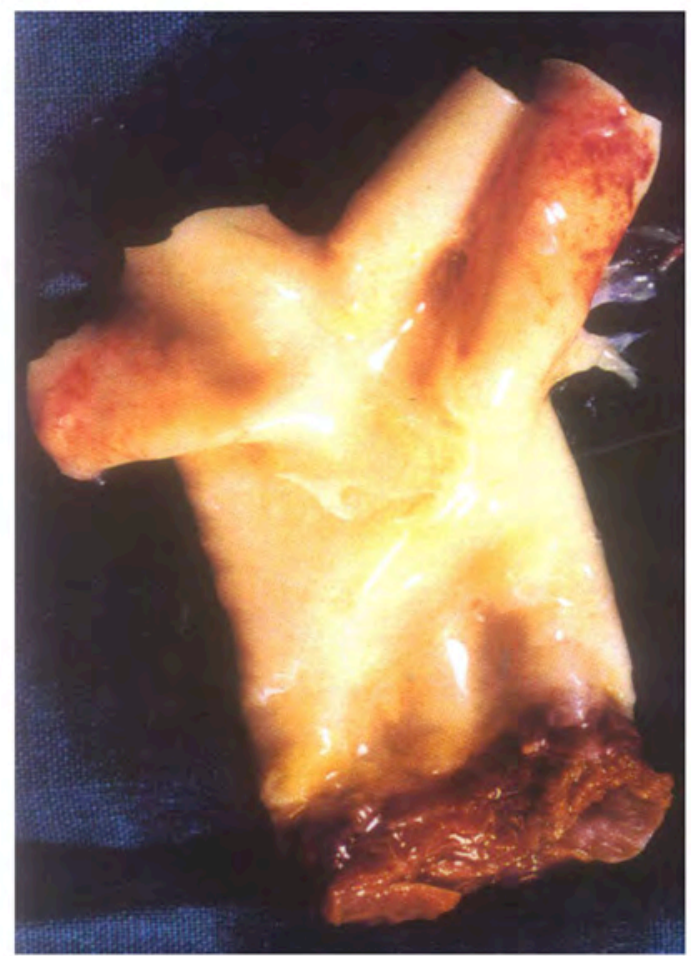

\section{Photographs of human semilunar heart valves}

The semilunar valves also possess blood vessels. The majority of them are present in the proximal portion near the myocardium, with few found in the cusps, which are nourished by diffusion from the blood in the heart because of their thinner structure.

The creation of a functional TEHV requires profound knowledge of the healthy valve structure, the biological processes associated with their development, and also their functional features and requirements for their formation. The main components that comprised the aortic valve are described in the following subsections.

\subsubsection{Valvular interstitial cells}

Valvular interstitial cells, the most abundant cell type in heart valves, are a heterogeneous population embedded in their own ECM. Liu et al. (Ref. 21) classified these cells in five different types: embryonic endothelial progenitor cells (EPCs) (Ref. 22), quiescent (Ref. 23), activated (Ref. 24, 25), progenitor (Ref. 26, 27, 28), and osteoblastic VICs (Ref. 29). They have particular characteristics and functions regulated by environmental conditions that are summarized in Table 1. VICs properties are also different in health and disease. For example VICs from aortic and mitral valve are stiffer than those from pulmonary and tricuspid, suggesting that VICs respond to local tissue stress by altering their stiffness (Ref. 30).

From the morphological point of view VICs have a fusiform and fibroblastic shape with prominent cytoplasmic extensions and an incomplete basal lamina (Ref. 31, 32). They are mainly characterised by their cytoplasm, which is rich in mitochondria, rough endoplasmic reticulum, and frequently exocytic vesicles (Ref. 33). VICs mediate matrix remodelling and also maintain valve homeostasis. They are crucial for supporting normal valve physiology, playing an important role in some pathological valve processes (Ref. 34).

\subsubsection{Valvular endothelial cells}

Valvular endothelial cells (VECs) are in charge of maintaining a non-thrombogenic surface, nutrient transport, and transduction of biochemical and mechanical signals in the heart valve. They are located in parallel to the ECM collagen fibres of valves and perpendicular to the blood flow direction (Ref. 35). VECs release factors that act on the underlying VICs, inhibiting their proliferation and increasing ECM synthesis (Ref. 36). They share some similarities with vascular endothelial cells. They present cobblestone-like morphology when cultured in vitro and also exhibit contact inhibition. Preliminary studies indicated that 
Expert Reviews in Molecular Medicine

subpopulations of these cells were also able to transdifferentiate into smooth muscle-like phenotype (Ref. 35). Moreover, VECs dysfunction seems to be involved in certain cardiovascular diseases (Ref. 37).

\subsubsection{Extracellular matrix}

The ECM is considered to be the main responsible for the durability of heart valves. As shown in Figure 2, its principal components are collagens type I and type III, elastin, glycosaminoglycans (GAGs), and proteoglycans (PGs). Collagens are fundamental for valve's biomechanical functions, providing stiffness and elasticity; moreover, they have a strong influence on cell adhesion and migration (Ref. 38). Microscopically, the three layers that make up the valve have different ECM composition. For instance the thinnest layer, the ventricularis, is mainly composed of elastin which provides elasticity (Ref. 39), whereas the thickest layer, the fibrosa that is in charge of providing mechanical strength and load resistance to the valve, mainly contains collagen I and III (3:1) and $2 \%$ of collagen type IV (Ref. 33, 40).

The spongiosa layer, responsible for the compressible stiffness required for proper heart valve function, contains mainly GAGs and PGs. GAGs are largely responsible for the huge waterabsorbing capacity of this layer thanks to the high concentration of negative charges that they carry. Furthermore, GAGs are also required for hydration of the spongiosa layer and absorb compressive forces, reducing flexural deformation (Ref. 41). Given their nature, GAGs can also reduce the calcification process by chelating calcium ions. All of these features are important factors which go towards explaining the mechanical behaviour of heart valve tissues. In particular GAGs are crucial components that must be considered when creating TEHVs. For instance, after the process of decellularization with detergents, GAG loss was observed in valve tissues, compromising their structure and functions (Ref. 42).

Heart valve ECM is subjected to dynamic remodelling, which is induced by VICs. The quantity and quality of ECM essentially depends on the nature of the VICs (Ref. 33, 40). The relationship between ECM organisation and VIC distribution is also crucial during development and in pathological states (Ref. 33). Walker et al. (Ref. 43) observed that various genes associated with ECM are mutated in congenital valve diseases, highlighting its importance in the morphology and functionality of heart valves.

\subsection{Heart valve biomechanics and related illnesses}

Mitral and aortic valves are in charge of pumping the blood, experiencing intense pressure, and supporting higher biomechanical stress than pulmonary and tricuspid. Therefore, they are more affected by pathologies and degenerative processes while alterations in pulmonary or tricuspid valves are less common and mainly related with genetic or foetal defects (Ref. 12). Valve pathologies are characterized within two functional groups: stenosis and regurgitation. Haemodinamically, the pulmonary valve flow profile is similar to that of the aortic, but the velocity magnitude is lower (Ref. 30). The slightly difference in the biomechanical and ultrastructural properties aforementioned in Section 2.1 strongly constraints the type of disease developed. Pathologies of the aortic valve can be triggered by inflammation or by degenerative valve disease, caused by aging coupled with rheumatic and infective endocarditis (Ref. 44). On the contrary, congenital stenosis is the most common pulmonary valve pathology, mainly caused by a defect during foetal development; this alteration is normally solved by surgery during infancy. Finally, mitral regurgitation, which can be caused by rheumatic fever, congenital abnormalities, ischemic heart disease or cardiomyopathies, is the most common functional abnormality of this valve.

\section{Cardiac valve problems and clinical strategies for their treatment: the importance of valve tissue banks.}




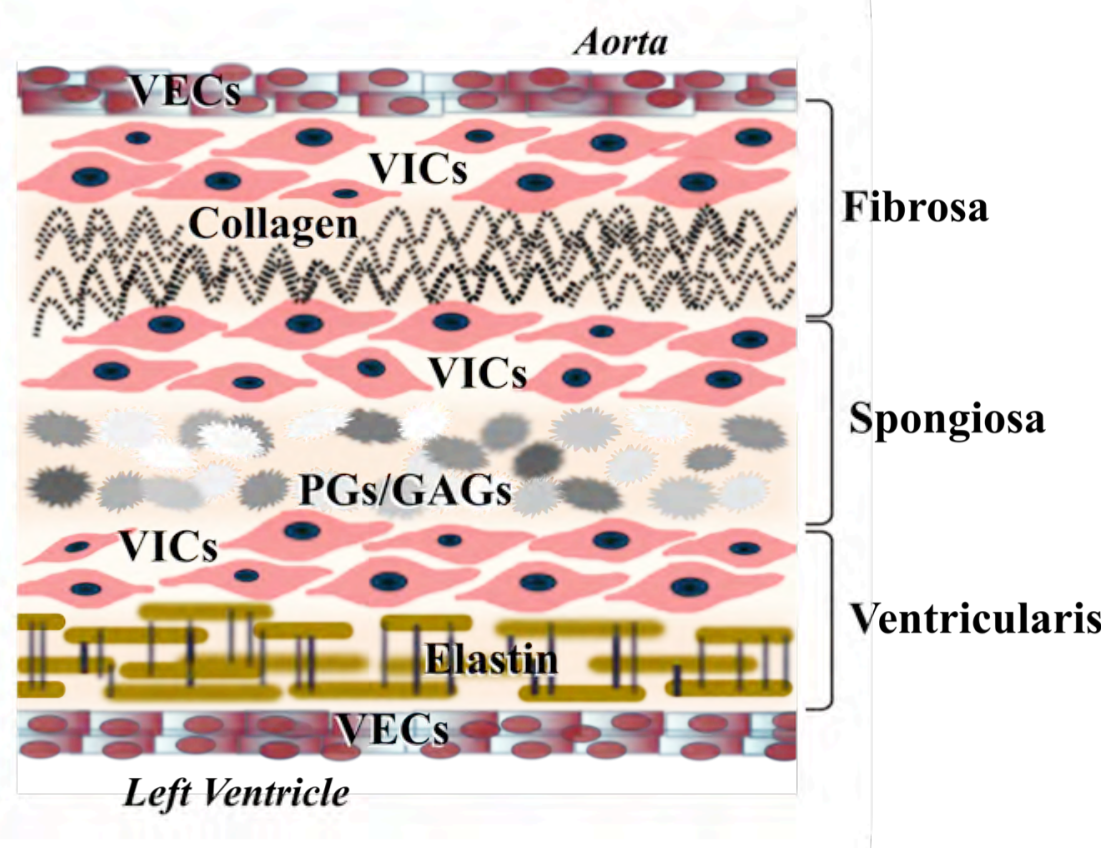

\section{Detailed heart valve structure}

As we mentioned above, different illnesses can compromise and damage the delicate structure of heart valves, triggering their alteration and causing the three main valve problems: regurgitation, stenosis and calcification. In the past the inflammation caused by rheumatic heart disease and endocarditis induced by bacterial infections were the root causes of valve alterations. Although these problems remain a major health roadblock in developing countries (Ref. 3), valve dysfunctions in the industrialized world are almost always caused by degenerative diseases, mostly as a result of aging and congenital defects (Ref. 11). Several drugs can be used as short-term therapies to improve the health and condition of patients with severe valvular pathologies, however in most cases the best option for correcting the problem is to proceed with valve repair surgery and/or replacement. The choice of surgical procedure is adapted to the team's experience, the presence of an aneurysm, the characteristics of the leaflets, and also to the patient's condition and life expectancy (Ref. 11).

Current alternatives for $\mathrm{HV}$ replacements are mechanical and biological (xenogeneic and allogeneic) implants (strategy A in Figure 3).

\subsection{Mechanical implants}

Since 1960, when Harken (Ref. 45) and Starr (Ref. 46) reported the first successful surgical doi:10.1017/erm.2015.15 implantations of a mechanical heart valve, their use has widespread and they are now the option selected in more than $50 \%$ of replacement surgeries. The main advantage is their high mechanical strength; but although mechanical implants are very resistant and work satisfactorily for years, they carry with them the risk of thrombosis generated by high shear stress, blood alterations or non-physiological flows (Ref. 47). Consequently, they generally imply the use of anticoagulant medication for the rest of the patient's life (Ref. 48).

\subsection{Bioprosthetic valves}

The bioprosthetic valves can be obtained from animal (xenografts) or human origin (autografts and allografts/ homografts). Compared with their mechanical counterparts, bioprostheses are affected by structural dysfunction due to tissue degeneration, so they need to be replaced within 10-15 years. For this reason current clinical guidelines recommend the use of bioprosthetic replacements in patients over 65 years (Ref. 15, 47).

Xenografts have usually bovine or porcine origin. Once extracted, they are fixed with glutaraldehyde (GA) to prevent rejection (by masking immunogenic epitopes) and zoonosis (Ref. 49). Animal valves do not induce clot formation but they entail a risk of xenoinfection and degrade faster (Ref. 50, 51). Their dysfunction is motivated 
due to tissue damage, mainly by calcification and collagen degradation.

Those detrimental processes seem to be triggered by the use of GA during fixation. Fixation with GA preserves the integrity of membrane phospholipids, which remain in the valve after the treatment. These lipids react with the surrounding extracellular calcium, creating aggregates and promoting valve calcification. Because calcification evolves faster in young patients, xenogeneic replacements are mainly prescribed in patients with high death risk or advanced age (Ref. 51).Moreover, GA degrades animal's VICs and VECs of valves, affecting also to the collagen matrix and destroying the functional structure. Once implanted, the receptor's cells are not able to restore the functionality, and they start to secrete altered ECM proteins profile, increasing the damage (Ref. 50). Several alternatives to solve this problem have been tried however, without great success (Ref. 52, 53).

Given their better hemodynamic profile, human allografts, or autografts in the case of Ross procedure, are currently the optimal solution, but due to their importance and peculiarities, they deserve a detailed study(Ref. 54).

\subsection{Human homografts and the importance of heart valye tissue banking}

Since the last century, thousands of heart valve homografts (especially aortic and pulmonary) have been used in reconstructive cardiac surgery and tissue replacement (Ref. 16, 44, 55, 56). One of the main differences between cardiac valve homografts and other tissues for transplantation (e.g. bone) is that the valve conduits need to perform at its best immediately after surgery. Additionally, the clinical outcome of an homograft can be conditioned by the physiologic process of inflammation, the biomechanical stress, the immune response and other molecular events.

Once the tissue has been transplanted, the analysis of factors which could play a significant role in its deterioration also remains as controversial issue. Cell viability is one of the most controversial topics at this point. Several authors have reported that maintaining the viability of cells residing within the graft have beneficial effects (Ref. 57); but donor cell viability is drastically few months after transplantation. As Hilbert and Koolbergen documented, instead of the donor cells, the valvular surface is covered by a fibrous sheath (Ref. 58, 59).

It is known that homograft immunogenicity is directly related to cell viability (Ref. 60). Cryopreserved homografts have been shown to elicit a donor-specific immune response at humoral and cellular levels (Ref. 61, 62). The necessity to address or not crossmatch for blood group is a clear example of contradictory opinions on this issue (Ref. 63, 64, 65). In any case, since endothelium is especially pointed for valve immunogenicity (Ref. 66), a strategy based on the elimination of this layer during tissue processing could be used to reduce this risk. Nevertheless, although host cells can colonize the matrix, endothelium reconstitution seems to be difficult (Ref. 60, 67) and the loss of this layer may lead to detrimental effects on the ECM (Ref. 59). Additionally, to what extent the immunological response affects homograft durability is still unclear (Ref. 66, 68, 69, 70)).

Other factors noted above can lead to apoptosis of donor cells in the transplanted homograft: prolonged ischemia, addition and removal of cryoprotectant solution, cooling and warming rates, ischemia-reperfusion injury (Ref. 58, 71). Homograft degeneration probably reflects the cumulative damage of several factors.

The use of proper manufacturing and storage practices to preserve the homografts until the moment of their transplant is also a key issue in the success of the implant. For this reason, cell and tissue banks and transplant organizations are the key guardians for preserving safety. The critical issues that may affect the safety and efficacy of the homografts are:

- Disease Transmission: Rigorous donor screening is actually the best available method to improve allograft safety (Ref. 72, 73).

- Tissue Assessment: Quality codes are assigned to homografts, depending on the presence of calcification, atheromas or fenestrations a morphological status is determined (Ref. 72, 74). These classifications are crucial during the decision-making process for tissue allocation. 
- Contamination: Tissue microbial contamination may arise from several sources such as the operation team (Ref. 75), the own donor, especially if death is caused by trauma or the heart has been recovered late after death. In order to prevent contamination, the control of processing area is also crucial. The homograft extraction needs to be performed in an aseptic clean room with grade B background and under sterile conditions (air quality class A) (Ref. 76). If the replacement needs to be frozen, storage in liquid nitrogen needs to be strictly controlled. Liquid nitrogen is not sterile and microorganisms survive at this ultra-low temperature (Ref. 77). A liquid environment acts as an efficient vehicle for microbial diffusion. For this reason, the bag containing the tissue is doubly wrapped using another bag (so called doublebagging), and sealed. It is common practice in cardiac valve banks, to ensure the immersion of tissues in an antibiotic cocktail immediately following collection. The length and temperature of incubation, as well as the concentration and type of antibiotics used, vary among banks (Ref. 78).

- Cell and tissue damage: Heart valve processing is not harmless and some important factors must be controlled to enhance cell viability (Ref. 71). Those factors are ischemia (Ref. 79, 80), freezing and thawing conditions (Ref. 81), or disinfection and storage of the samples before their use.

Native heart valves are dynamic structures that are in continuous remodelling to adapt the hemodynamic necessities. As we already mentioned, interstitial cell viability may enable continuous remodelling (Ref. 66, 82) and fibroblastic matrix cells are immunologically well tolerated. Koolbergen et al. found fibroblastic donor cells in vessel walls several years posttransplantation (Ref. 67).

None of the current replacements is able to restore completely the capacities and functions of native valves, so in the end, after several years cardiac function may be compromised. As we already mentioned, this is especially crucial for children and young adults suffering cardiac valve problems. In those cases, as well as in particularly active older people, the most successful valve replacement approach is the Ross procedure (Ref. 16). This procedure is a specialized valve surgery where the diseased aortic valve is replaced by patient's own pulmonary valve, and then this is substituted with a cadaveric pulmonary homograft. Ross procedure offers several advantages over replacements with biological or mechanical prosthesis.

First, in the case of paediatric patients, the pulmonary autograft can continue growing in the aortic position according with the recipient with higher longevity than xenografts. Anticoagulation treatment, which is required for mechanical replacements, is not necessary after Ross procedure. This is especially beneficial for women that want to have children because anticoagulation drugs are contraindicated during pregnancy. However, especially in the case of children, this replacement procedure may fail. After the relocation in aortic position, pulmonary valve composition can be altered due to the higher biomechanical demand that aortic valve supports. Additionally, the pulmonary autograft transplanted during Ross procedure, needs to be replaced at some point (Ref. 65, 83). Despite the fact that human homografts seem to be the most physiologically suitable substitutes (Ref. 11), the number of cadaveric donor valves cannot meet current demands. For this reason finding a suitable TE solution is especially challenging in paediatric or young patients.

\section{Tissue-engineered heart valves}

Heart valve tissue engineering represent a promising strategy to create prostheses with similar functional and biomechanical properties to native heart valves (Ref. 84). They should be able to withstand the repetitive changes in shape, dimensions, and stress generated by the opening and closing cycles they are subjected to during cardiac beating (Ref. 85). Similarly, the TEHVs should solve some of the common limitations that still remain in commercially available prostheses and have a direct impact on the clinical outcome (Ref. 86): thrombogenicity, calcification, and high immunogenicity, among others. Poor biomechanical properties or inadequate ECM composition of TEHVs could induce stenosis, 


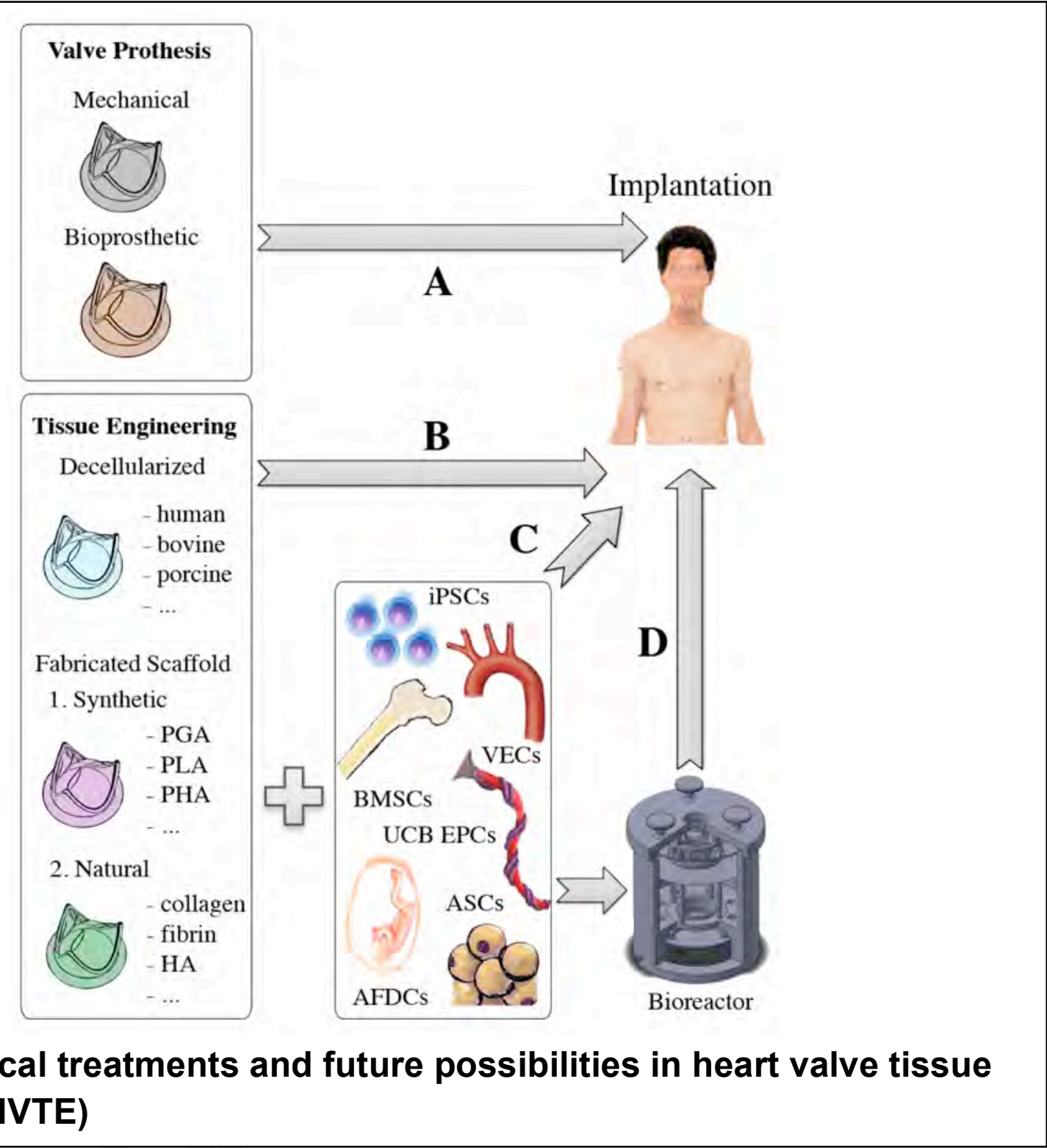

valve regurgitation, or low transvalvular pressure gradient of the incumbent valve.

Regarding paediatric patients, their implanted TEHVs should be capable of growing and remodelling according to the stage of patient's life, responding to biological signals, and initiating selfrepair operations after small damaging events in the same way that native valves respond. Eventually, the TEHVs should be able to integrate themselves into the patient's tissue. Taken together, these requirements should be accomplished whilst integrating all individual components of the TEHV into a synergistic design.

The fabrication of functional, viable, and human implantable prostheses depends on three substantial components widely known as TE triad: cells, scaffolds, and signalling molecules (Ref. 87). The following sections focus on two of these building blocks and the decisions affecting them during the creation of TEHVs: the selection of the cell type and the fabrication of the scaffold. Clinical ongoing solutions and future possibilities based on TE are summarized in Figure 3 (options A, B, and C). Additionally, the progresses reached in TE through in vitro studies, preclinical studies, and clinical trials are summarized in Tables 2, 3, and 4, respectively.

\subsection{Challenge 1: Selecting biomaterials for scaffolds}

The success of the TEHV strongly depends on the biocompatible materials selected to construct the scaffold and the resulting physicochemical properties (Ref. 88). The scaffold is the threedimensional (3D) structure that allows cells to adhere, generate ECM, grow, migrate, and also differentiate. Some crucial processes that can 
Expert Reviews in Molecular Medicine

guarantee the full integration of the implant into the heart.

The scaffolds of TEHVs face important challenges in terms of integrity, mechanical strength, calcification resistance, and thrombosis risk; but even more important, they must be prepared to deal with the cardiac environment conditions immediately upon implantation (Ref. 89). As shown in Figure 3, there are mainly two types of scaffold for HVTE: acellular native valves and artificially engineered scaffolds; in case of the latter, its constituents need to be carefully considered, since the aim is to mimic the native valve anatomy and functionality.

Finally, the materials selected must be suitable for different manufacturing processes and reasonably accessible, enabling mass production that caters to the important demand in a shorter time than the currently available (Ref. 90).

\subsubsection{Decellularized cardiac valve scaffolds from allogeneic/xenogeneic sources}

Traditionally, decellularized heart valves and pericardium tissues from sheep, cows and pigs have been selected as scaffolds due to the shortage of human valve allografts (Ref. 91). The decellularization methods use detergents, chelating agents, proteolytic enzymes, or combinations thereof (Ref. 92). Other alternatives applied include the use of electrical pulses, hydrostatic pressure, or freeze-thaw cycles (Ref. 18).

The main advantages of decellularization are the retention of the original structure as well as many ECM proteins, preservation of the mechanical properties, and a relatively low cost. However, there are serious limitations such as the possibility of disease transmission, or excessively high density and stiffness. Moreover, the porosity is especially low on valves decellularized and treated with crosslinking agents. A failure in the decellularization process has detrimental consequences for patients as shown in the SynerGRaft trial (Ref. 93). However, the necessity of re-seeding or not a valve after decellularization is still the subject of an intense debate. Some authors argue that in vitro recellularization is not a realistic strategy that can be translated into routine clinical practices because of its high financial and time costs (Ref. 94). Indeed, some studies doi:10.1017/erm.2015.15 demonstrate that the seeded cells do not survive when the valve is introduced into the patient and that the host's cells may be the origin of the observed repopulation (Ref. 91). A summary of reported clinical experiences is given in Table 2 . It should be noted that this strategy, which is labelled as B in Figure 3, is the one that has gone further of all TEHV approaches concerning clinical trials (Ref. 95, 96, 97).

Important differences in cell growth when compared to human-source matrices were demonstrated after seeding human cells over them (Ref. 98). The use of multilayer VEGF/heparin or chitosan/heparin films to cover the decellularized valve has demonstrated to increase in vitro adhesion and proliferation of endothelial progenitor cells (EPCs). This has resulted in an improved decellularized valve haemocompatibility and a reduced risk of thrombosis (Ref. 99, 100).

Although it has been proved that host cells can recolonize the scaffold, a study comparing native heart valves with decellularized and recolonized ones, concluded that the cell types present in the manipulated structures are different from the native ones. This may interfere in the normal function and/or stability of the valve. Additionally, the limited re-endothelization that can be achieved in decellularized matrices can compromise their integration and long term viability. In vivo recellularization studies have stated that pretreatment with host cells can improve scaffold's biocompatibility reducing calcinosis (Ref. 101). Therefore, a short-term incubation of the scaffold with cells and/or unprocessed cell preparations from the patient seems to help in both the recellularization and cell survival outcomes (Ref. 94, 102). Another alternative is to enhance autologous recellularization after implantation coating the acellular scaffolds with biological components (Ref. 100), or with CD133 antibodies (Ref. 103).

\subsubsection{Artificially engineered scaffolds}

The alternative to decellularization seems to be de novo construction of natural or synthetic scaffolds using biocompatible and biodegradable materials. The ideal artificial scaffold should take into account the anisotropy and heterogeneity of native valves. Two types of scaffold for TEHVs are usually created: fibrous and porous. The classical method for manufacture porous scaffolds has been 
to mould thermoplastic biomaterials into $3 \mathrm{D}$ structures (Ref. 104, 105, 106). In the case of fibrous scaffolds, electrospinning, due to its applicability and simplicity, is by far the most commonly used technique to prepare the nanofibers for the scaffold. This technology is based on the continuous elongation of a viscoelastic flow derived from a polymer solution (Ref. 107). Drops of polymer, created with a syringe, are electrified and ejected by electrostatic repulsions, producing long and thin fibres. They are finally collected with a mould that can have easily the desired shape of the heart valve (Ref. 108, 109). Other technique is the knitting, in which 2D flat sheets with wellinterconnected pores are created using drawn filaments of polymer. However, current electrospinning moulding techniques and knitting systems may soon be replaced by more flexible additive manufacturing (AM) processes (Ref. 110).

Most of the conventional manufacturing procedures generate components with different degrees of stiffness that need to be subsequently joined together by biocompatible suture or glues such as bovine serum albumin-glutaraldehyde (Ref. 111). AM can overcome these limitations. For instance, stereolithography is a technology more suitable to create complex and heterogeneous scaffolds. This technique first can create a scaffold of hydrogel, which is subsequently cross-linked with ultraviolet light (Ref. 112). Nevertheless, the use of cytotoxic wavelengths and the necessity of additional coating to improve cell adhesion means that further research in this field is imperative in order to find more realistic alternatives.

\section{A. Fabricated scaffolds from synthetic materials}

The production of synthetic scaffolds can be easily controlled allowing reproducibility, standardization, and stable properties. Theoretically, they are designed to create bioabsorbable matrices that act as transitional platforms until the seeded cells replace the synthetic polymers by natural ECM proteins. The synthetic scaffolds can be produced cost-effectively with enough strength and stiffness, and showing important advantages such as low thrombogenicity, and immunogenicity. However, their structural complexity, shape and elastomeric properties are still far from decellularized valves or native tissue.

Numerous synthetic materials have been tested including, polyglactin (Ref. 113), polyglycolic acid
(PGA) (Ref. 114, 115), polylactic acid (PLA), copolymer of PGA and PLA, (PLGA) (Ref. 104), polyhydroxyalkanoate (PHA) (Ref. 116), polyether urethane (PEU) (Ref. 117), polyester urethane urea (PEUU) (Ref. 108), polycarbonate urethane (Ref. 118), poly-e-caprolactone (PCL) (Ref. 119), poly(glycerol-sebacate) (PGS) (Ref. 120), polydioxanone (PDO) (Ref. 109), among others. While several combinations of these polymers can be found in the literature (Ref. 116, 119), few studies have systematically compared them to single ones; therefore, it is difficult to establish the prevalence of anyone of them over the rest.

PHA seems to be the biomaterial family most often used for creating highly porous solid scaffolds when preparing scaffolds for 3-leaflet heart valves. On the contrary, most of fibrous scaffolds seem to be produced from PGA using mechanical drawing or electrospinning. PHA shows a wide range of mechanical and thermal properties, but, above all, it stands out because it may be manipulated using a wide range of processing techniques (Ref. 105). Mitchell et al. demonstrated that the vascular scaffolds made of polyglactin/PGA copolymer were unstable, inducing aneurysm formation (Ref. 121). PGA combined with PLA improves scaffold properties such as less water absorption and reduced degradation rate (Ref. 86, 122, 123, 124). Stock et al. proved the superior properties of using hydroxyoctanoate (PHO) instead of PLA in terms of cell proliferation and scaffold stiffness (Ref. 125). PGA/PHO scaffolds coated with laminin and seeded with endothelial cells and vascular medial cells produced functional TEHVs after implanted in animals for up to 6 months. Also it has been described the thermo-plasticity showed by 3-leaflet valve scaffolds of nonwoven PGA mesh coated with poly-4-hydroxybutyrate (P4HB) (Ref. 4, 106).

The synthetic scaffolds can be coated with ECM proteins such as those present in plasma or platelet enriched plasma (Ref. 126) or other proteins such as growth factors, which enable targeted promotion of particular tissue growth (Ref. 26). ECM proteins provide not only additional structural support but also cell receptors, and binding sites (Ref. 127, 128). Their use improves the biocompatibility of the scaffold, and provides better cell adhesion, growth and differentiation. Therefore, as a natural evolution to the use of synthetic valves, the scaffolds can also be constructed with biological ECM proteins. 


\section{B. Fabricated scaffolds from natural materials}

Various studies have reported the use of collagen, hyaluronic acid (HA), fibrin, chitosan, or combinations thereof, to create biological protein based scaffolds (Ref. 111, 129, 130). Moulded TEHVs composed of fibrin gel and fibroblasts (FBs) have already been produced with the capacity to withstand backpressure commensurate with aortic valves in regurgitation tests (Ref. 131). In a sheep model, a pilot study demonstrated the potential of fibrinogen to create TEHVs with excellent tissue remodelling and structural durability after 3 months in vivo (Ref. 132).

A summary of representative in vitro studies using different biomaterials and manufacturing methods is given in Table 3 . Note that many of the in vitro studies highlight the resulting constructions are characterized by weak matrices and poor mechanical properties. This and the fact that it is hard to obtain sufficient amount of the proteins required, indicate that alternative sources, such as cultured human cells, should be found to avoid the risk of zoonosis from animal components (Ref. 133). It is certainly clear that human collagen or fibrin-based valves are far from being feasible.

\subsubsection{Other approaches for HVTE}

Among other AM approaches, 3D printing is one of the most promising technologies that would allow the construction of fully customized TEHVs with accurate geometry, and controlled properties designed to suit patients' specific needs. Enhanced levels of complexity might be achieved by the inclusion of various materials and cell types simultaneously at each step of the manufacturing process (Ref. 134). A proof of concept has already been performed by Butcher's group using the opensource 3D printer Fab@home (Ref. 112, 135). In general, this approach uses cell encapsulated in synthetic and/or natural hydrogels to generate heterogeneous and multi-scaled biological constructions. For instance, inkjet printing, which can fuse scaffold construction and recellularization into one step, allows the addition of different cell types during valve generation providing a better integration of the components (Ref. 136). All of these are still early stage technologies that promise less labour-intensive fabrication of patient-specific TEHVs.

\subsection{Challenge 2: Cell candidates for TEHVS}

In all TE systems, the cells are the commanders of regeneration, while the rest of the components act as a biological support (Ref. 137). For this reason, a proper selection of the cell types is the key part to succeed. An ideal candidate must satisfy the following criteria. First, cells should be in the appropriate differentiation status for re-establishing the desired functions, supporting mechanical loads, and synthesizing ECM proteins (Ref. 12). Second, they should be immune-compatible. So, the best scenario would be the use of autologous cells because native heart valve cells have the most suitable phenotype, and the potential to synthesize ECM and remodel the bioscaffold (Ref. 138); however, their low availability, and the isolation and maintenance difficulties associated with them are serious impediments.

In this section, we present recent progress in the search for cell candidates as well as some conclusions derived from the studies performed. The cell types selected should be able to produce all cell populations in the heart valve. To cover these issues we include in this paper the advances made in HVTE using different cell types such embryonic stem cells (ESCs), induced pluripotent stem cells (IPSs) and even foetal cells, which represent the main candidate to generate prenatal constructs (Figure 3).

\subsubsection{Adult Stem cells}

\section{A. Vascular endothelial cells}

They play an important role in valvular function, reducing the risk of coagulation and preventing inflammatory complications. If they are maintained in static culture, the vascular ECs share some similarities with VECs but under steady flow, as we mentioned above, the vascular ECs align perpendicularly to flow direction as vascular smooth muscle cells (SMCs) do (Butcher, 2004 \#390). For this reason, different vascular ECs have been tried as a source for VECs.

Several groups have used the vascular tissue as a source for extract VECs and recellularize different scaffolds. For example, vascular myofibroblasts (MFs) from human aortic tissue can survive and generate mature collagen matrix in ECM-coated 
Expert Reviews in Molecular Medicine

PGA scaffolds (Ref. 139), fibrin gel structures (Ref. 140), and scaffold-free tissues (Ref. 141, 142). More accessible venous tissue, such as the saphenous vein, can also be useful for isolating MFs. These produce harder and more mechanically resistant ECM than their arterial counterparts (Ref. 143, 144).

In some cases, those works have also get ahead towards in vivo studies using animal models. Pulmonary valve leaflets were exchanged by PGA scaffolds and then seeded with arterial FBs and vascular ECs in lambs (Ref. 113). Additional studies were able to prove that the implanted cells were still alive 8 weeks after transplantation (Ref. 114). This approach was improved by the addition of a preconditioning step and coating the scaffold with P4HB (Ref. 145).

The same seeding strategy, but with autologous MFs and vascular ECs, was attempted in decellularized sheep heart valves. Although a complete restitution was observed, histological signs of inflammatory reaction were observed in the subvalvar muscle (Ref. 146). Autologous arterial vascular ECs seeded on fibrin scaffolds were also capable of integrate in adult sheep pulmonary valves; but some degree of leaflet insufficiency after 3 months follow-up was revealed due to tissue contraction (Ref. 132). This issue may be resolved by the addition of other proteins in the scaffold to increase its resistance and stability. The feasibility of vascular tissuederived cells has also been evaluated in several clinical trials. A decellularized cryopreserved pulmonary allograft was seeded with autologous vascular ECs isolated from patient's forearm vein to create a viable TEHV; the right ventricular outflow tract was successfully reconstructed after Ross procedure (Ref. 147). Similar results were observed in 11 patients at 10 years follow-up (Ref. 148). Same procedure, but with porcine decellularized valves, did not show any statistically significant difference with the allografts, opening the possibility to solve the limitations of allografts (Ref. 149).

The use of non-valvular ECs in an aortic valve substitute, may sacrifice important functional behaviour. It is currently unknown if the dissimilar responses of vascular ECs and VECs against fluid flow has any effect on overall leaflet function, but different responses may imply altered paracrine signalling to surrounding cells. The main shortcomings of the vascular ECs are their limited availability and low proliferation rate. Moreover, the potential benefits are scarce because isolation of autologous cells requires the destruction of healthy structures and harmful surgical procedures (Ref. $150)$.

\section{B. Endothelial progenitor cells}

Circulating EPCs (Ref. 151) are one of the most promising cell types to solve the problem of the amount of ECs needed for engineering HVs. These cells, characterised by the expression of CD34 and VEGF2, are able to proliferate and generate endothelial structures both in vitro and in vivo (Ref. 152). EPCs are supposed to be recruited towards cardiac tissue in patients with coronal problems such as aortic valve regurgitation, dysfunctional congenitally-bicuspid aortic valves, aortic valve stenosis, or after coronary artery bypass grafting (Ref. 153, 154, 155, 156, 157). EPCs express endothelial markers such as CD31, VE-Cadherin, and eNOS; and after seeding they also express $\alpha \mathrm{SM}$ actin, MMP2/9, and metalloproteinase inhibitors (Ref. 158, 159). Treatments with VEGF and TGF1 $\beta$ can induce EPC endothelial to mesenchymal transition. In fact, some authors suggest that they correspond to the hypothetical group of valvular progenitors that controls normal heart valve repair (Ref. 160).

The potential of EPCs in TEHV has been tested in few in vitro (Table 2) and in vivo studies with encouraging results. A summary of some of the most representative pre-clinical investigations involving different HVTE strategies is given in Table 3. Coating a PGA scaffold with P4HB was found to improve EPC adhesion (Ref. 115, 158), similarly, the generation of a heparin/VEGF or chitosan/VEGF multilayer film increased EPC proliferation, adhesion, and migration in decellularized porcine aortic valves (Ref. 99, 100).

Their feasibility has also been tested in vivo through a clinical study performed by Cebotari et al. (Ref. 161). A three and a half year follow-up on two paediatric patients who underwent surgical implantation of human pulmonary valves incubated with peripheral mononuclear cells containing EPCs showed some remarkable findings: Both patient's valves had significantly increased in size as the patients matured without any sign of valvular degradation, and only mild regurgitation was 
Expert Reviews in Molecular Medicine

observed. Nevertheless, the exact role of the EPCs in this improvement remained unclear.

\section{Mesenchymal stem cells from bone marrow}

Because VICs have an intermediate endothelialmesenchymal behaviour and phenotype, mesenchymal stem cells (MSCs) are also being widely studied. These cells can be expanded easily in vitro, differentiate into several cell lineages, produce and organise ECM in a very similar way to native heart valve cells (Ref. 162), and can also respond to mechanical stimuli, adapting their morphology, marker expression, protein production, and migration (Ref. 163). Moreover, they also have important immunomodulatory properties (Ref. 164). In the two following sections we detail the most important sources of MSCs and their properties.

Probably the most characterised source of adult MSCs is the stromal fraction of BMSCs which have non-hematopoietic mesenchymal features and share more than $80 \%$ of their markers with VICs (Ref. 165). Experiments with chimeric mice transplanted with green fluorescent protein (GFP)expressing BMSCs demonstrated that they are recruited to the heart valve as part of normal homeostasis (Ref. 28, 166), and that their circulation and recruitment is also enhanced in patients who underwent coronary surgery. Similarly granulocyte-colony-stimulating factor treatment in a clinical trial was also shown to promote BMSC mobilisation towards heart valves, although no significant functional improvement was observed compared to untreated patients.

BMSCs have a good capacity to adhere, colonize, proliferate, and differentiate when seeded into many types of synthetic materials such as PGA/PLA (Ref. 86, 122, 123, 124), PGA/PH4B (Ref. 167, 168), or poly-propylene carbonate (Ref. 169); but also into biological collagen scaffolds (Ref. 111), fibrin complexes (Ref. 170, 171, 172, 173), and decellularized tissues (Ref. 171, 172, 173).

In general, these in vitro studies concluded that BMSCs produced stable structures with an ECM and cellular composition very similar to the native valve. BMSCs have been also used to perform in vivo studies. For example, autologous BMSCs seeded in a biodegradable PGA/PLLA scaffold were implanted in sheep allowing long-term functional recuperation (longer than 4 months)(Ref. 86). Similar experiments using neonatal BMSCs also concluded that the construct diameter remained unaltered after 20 weeks, although pulmonary regurgitation was detected after 6 weeks due to the decrease in the cusp dimension (Ref. 124).

The process of BMSCs differentiation towards a VIC-like phenotype has been addressed from various perspectives. The classical epigenetic stimulation has been conducted with vascular endothelial growth factor (VEGF) and transforming growth factor $\beta 1$ and $\beta 2$ (TGF $\beta 1$, TGF $\beta 2$ ) (Ref. 171). Apart from these two, it has been also tested the vector-induced expression of the fibroblast growth factor-inducible 14 (Fn14) differentiation factor (Ref. 174) and other functional proteins such as eNOS (Ref. 169). Nevertheless, exposure to mechanical stress is essential for their full differentiation toward ECs: after flow-rate stimulation BMSCs showed better integration into the scaffold, differentiation, migration, and ECM production (Ref. 175). This phenomenon is not exclusive to BMSCs and it has been also reported in EPCs and adipose-derived stem cells (ADSCs), among others. Moreover, this effect was even higher with combined flex-stretch-flow treatment in special bioreactors (Ref. 111, 123, 176).

BMSCs can generate cells from many cell lineages. Nevertheless, the complete differentiation of the total population must be addressed carefully, not only to obtain fully functional cells, but also to reduce the possibility of transdifferentiation. For example, BMSC exposure to mechanical tension seems to induce the expression of chondrogenic and osteogenic proteins, promoting valve calcification and compromising graft viability (Ref. 177). Comparative studies with ECs and SMCs revealed that constructions seeded with CD133+ BMSCs showed lower calcification and inflammation accompanied by a higher transvalvular gradient (Ref. 178).

Another important issue is that proliferation and differentiation of BMSCs may be altered in older patients, thus, bone marrow might not be a viable source of autologous cells in many of these patients (Ref. 173).

Some authors have worked directly with the bone marrow mononuclear cell (BMMC) fraction. This cell type shows a remarkable potential to adhere, 
grow, and differentiate in GA-fixed valves detoxicated with citric acid (Ref. 179), or coated with plasma or platelet-enriched-plasma (Ref. 126), but his was not the case of fibrin-coated synthetic scaffolds. BMMCs seeded and incubated with them for short amounts of time did not increase cell integration after implantation neither in sheep (Ref. 94) nor in non-human primates (Ref. 180). Compared to BMSCs, the recellularization of porcine scaffolds with BMMCs produced a higher inflammatory cell infiltration and valve thickness (Ref. 172). This reaction is maybe due to the fact that BMMC fraction attracts endogenous cells such as monocytes, promoting regeneration via adjacent blood vessels (Ref. 181).

\section{Mesenchymal stem cells from adipose tissue}

Among the MSCs obtained from other sources, human ASCs have emerged as strong candidates to play a crucial role in TE and regenerative medicine for several reasons. They can be easily harvested from an abundant source, the fat tissue. The cell yield per gram of fat tissue is about 500-fold that obtained for BMSCs (Ref. 182, 183). They can be isolated with greater success than in other foetal or adult sources due to their higher colony-forming unit capacity (Ref. 184, 185). ASCs show high rate of proliferation in vitro and have multipotent ability to differentiate towards different types of MSC. Therefore, ASCs can be a virtually infinite supply of SCs, making them not only a good candidate for heart valve construction but also for generating other cardiac structures such as vascular bypass grafts (Ref. 186).

The ASCs, like their bone marrow counterparts, do not trigger the response of allogeneic lymphocytes in vitro (Ref. 187). They have an immunophenotype which is very similar to other MSCs, however, no studies have been performed to test their potential in vivo. One of the reasons could be that although they are capable of undergoing mesenchymal to endothelial transformation in response to mechanical changes or to the addition of factors like VEGF, current differentiation methods do not produce cells capable of expressing important markers such as eNOS (Ref. 188, 189).

The ASCs have shown a great potential in the preliminary studies in vitro. When their behaviour in PGA/PH4B scaffolds is compared with human BMSCs or VICs, they showed higher elastin, collagen, and GAG production; they also have a higher migration rate and are more uniformly distributed within the scaffold, which is thought to be due to their higher expression of $\alpha-S M$ actin (Ref. 162). Further experiments in order to optimize their final differentiation to adapt them to the cellular requirements must be address to test the feasibility of this promising source of cells.

\subsubsection{Prenatal extraembryonic cell sources}

In addition to the abovementioned adult SCs, foetal and extra-foetal tissues represent additional sources of SCs. As we mentioned above the paediatric problem is one of the challenges in cardiovascular treatments. The finding of autologous, viable and growing replacements such as TEHVs would reduce the insurmountable therapeutic limitations in the treatment of children carrying congenital heart diseases. The majority of these cardiac defects can be detected around week 20 of pregnancy. Autologous stem/progenitor cells can be isolated from several of the foetal annex structures, without damage or compromise the foetus itself. The relevant cells prenatally harvested are amniotic fluid-derived cells (AFDCs), chorionic villi-derived mesenchymal progenitor cells, and umbilical cord blood (UCB) derived EPCs (Ref. 102). The cells obtained show a higher expansion rate and plasticity to produce a wider variety of cell lineages that can be used for autologous TEHV implants at birth or prenatally.

\section{A. Amniotic fluid-derived cells}

Amniotic fluid represents an attractive foetal cell source for the concept of paediatric heart valve tissue engineering since it renders possible prenatal access to foetal cells from all three germ layers via a low-risk procedure (Ref. 150). The amniotic fluid, generally obtained from amniocentesis or amnioreduction, contains a heterogeneous cell population with a small percentage of cells showing stem cell features (Ref. 190). The AFDCs present not only an intermediate growth rate between embryonic and MSCs, but also a phenotype which includes early stemness markers and MSC-like signatures (Ref. 191, 192). In fact, AFDCs can be reverted into a pluripotent state or generating ECs after adequate stimulation (Ref. 193, 194). The feasibility of generating living autologous heart valve leaflets in vitro using human amniotic fluid as a single cell source and also by combination of mesenchymal ADCs with amniotic 


\section{Expert Reviews in Molecular Medicine}

fluid endothelial precursors has been already attempted (Ref. 195). This research group also demonstrated the in vivo functionality of autologous AFDCs seeded over biodegradable PGA/P4HB scaffolds and transplanted into sheep fetuses before birth (Ref. 196, 197).

\section{B. Chorionic villi-derived mesenchymal stem cells}

The chorion is one of the membranes that conform the human placenta. This membrane is composed for maternal mesoderm tissue embedded between mesenchymal and trophoblastic cells with foetal origin, called chorionic villi. Biopsy of chorionic villi cells is routinely performed for prenatal genetic diagnostics because provides foetal mesenchymal cells, including foetal progenitor cells, located out of the foetus.

When isolated from an early developmental stage, chorionic villi cells exhibit profound stem cell-like properties, for this reason they are a promising cell source for paediatric tissue engineering applications (Ref. 102). Schmidt et al. (Ref. 196) have demonstrated the feasibility of this approach for HVTE by using chorionic villi-derived mesenchymal cells for the fabrication of viable heart valve leaflets in vitro, with promising results. The greatest roadblock in these initial studies is the overgrowth of maternal cells, that sometimes are also present in the samples a fact that needs to be avoided in the future., chorionic villi samples also contain foetal capillary endothelial cells, which might also be isolated using cell sorting techniques as part of future therapeutic attempts (Ref. 198).

\section{Umbilical cord blood derived-end othelial progenitor cells}

The umbilical cord is a common source of hematopoietic cells, but it may also become an invaluable source of non-hematopoietic SCs, the UCB-derived EPCs. They are attractive candidates for enhancing the biocompatibility of mechanical valves. UCB-derived EPCs have already been successfully used to seed decellularized valves (Ref. 199), and mechanical valves made of hydroxyapatite (Ref. 200), or titanium (Ref. 201). The idea of reseed a graft using this cell type would be specially useful in cases of fetal cardiopathies that require valve replacement. Furthermore, human UCB-derived FBs and EPCs have been successfully used to generate living patches on
PGA/P4HB scaffolds (Ref. 202) and tissueengineered blood vessels (Ref. 203). In order to assure their feasibility, it must be tested whether these cells can acquire the dual mesenchymalendothelial phenotype, which is required for their proper function in the tissue.

\subsubsection{Embryonic and induced pluripotent stem cells}

Embryonic stem cells (ESCs) are theoretically capable of recapitulating the whole valvulogenesis process. Indeed, their high expansion rate and pluripotency make them stand out from other cell types. Ethical issues could be overcome using nondestructive embryonic manipulation methods; however, and despite their demonstrated potential, two important shortcomings discourage their use in TE applications: high risk of teratoma formation and xenorejection. The latter could be circumvented by the use of induced pluripotent stem cells (iPSCs). Despite of their adult tissue origin, iPSCs are grouped together with ESCs due to their similarities and pluripotent capacities.

iPSCs are generated by inducing the expression of certain stemness genes in adult differentiated cells extracted from patient's own tissues (Ref. 204). Recently, they have been proven to be capable of repopulating decellularized mouse heart valves (Ref. 205), but the generation of functional TEHVs requires further research, especially in controlling cell differentiation. Although the promise of revolutionary improvements in TE, patient-derived iPSCs are still far from clinical practice; they still represent valuable models to study the origin and development of heart valves.

\section{Conclusion and future outlook}

The ideal replacement for heart valves would be an alive and immune-compatible implant containing both endothelial and interstitial cells. These cells must produce and remodel the appropriate ECM to address the growth of the graft in accordance with patient's development. The structure of the TEHVs also needs to be fully functional in terms of hemodynamics and biomechanics immediately upon implantation. For now, none of the available solutions in the market accomplish all these requirements. 
Mechanical and biological heart valve prosthesis, as mentioned before, continue as the gold standard in surgical replacement procedures, saving millions of lives. However, both lack the properties of living replacements, with the subsequent inability to regenerate and growth. Additionally, mechanical substitutes also carry with them the side effects of anticoagulation drugs. For the moment, homografts and autografts appear to be the best clinical solution. But considering the evolution of modern society, the age of potential homograft donors is constantly increasing because of the aging of the population in general. This suggests that the availability and quality of the donated organs is decreasing. In addition, the heterogeneous cellular composition of native valves indicates that different cell types should be seeded sequentially or simultaneously to reach the most realistic approach to create TEHVs. Innovative advances such as noninvasive imaging systems to monitoring the tissue regeneration or new flexible manufacturing techniques might be introduce in the equation. For all these reasons we firmly believe the best solution to this important social-sanitary problem is yet to come and probably remains hidden in the laboratory.

We have come a long way since Vacanti attempted the creation of a TEHV almost 20 years ago. The progress is remarkable in many senses, especially due to recent advances on SC and biodegradable scaffolds, but few advances in HVTE have reached clinical stage. This can be due to several reasons, often interrelated; in our opinion, and considering the heterogeneous cellular composition of the native valves, the complexity of constructions needs to be drastically increased. Current scaffolds also fail to provide the proper properties in terms of morphology and biomechanics that promising artificial implants require to be capable of addressing current limitations of donor supply shortage. They also need to be manufactured with a composition and internal structure that makes them able to convey and release growth factors required in the cell niche of TEHVs.

Additional effort must be given to assess the safety and efficacy of TEHVs before they will be ready to clinical routine. First, based on accumulated experience, it is mandatory to standardize and optimize the combinations of different candidate cells, biomaterials and culture conditions, establishing the criteria to correlate in vitro outcomes with in vivo experiments. Deeper in vitro characterization of TEHVs at structural and functional levels should be carried out, and additional strategies and criteria are required to this end. Current in vivo models must be replaced by others that better reflects the properties of human cardiac valves. Until now, the ovine model is routinely employed in preclinical studies, but the hemodynamic characteristics of sheep valve significantly differ from human ones. Therefore this might not be a good model to perform preclinical studies.

Finally, it would be very beneficial for the field to join efforts and obtain global conclusions about the on-going research on HVTE. In this sense, the creation of databases for lending the standardization of in vitro TEHV results should be an interesting strategy. Develop an strict preclinical (in vitro and in vivo) quality control criteria before attempt clinical trials is also mandatory. Finally, enormous research effort will be also necessary to analyse and predict the individual response among patients.

In our opinion, progress in the field will require laboratories with advanced technologies and novel manufacturing strategies and multidisciplinary teams in which close collaboration between developmental biologists, surgeons, engineers, polymer chemists and pharmacists will provide new insights. Without any doubt, we can asses that it will be sometime before we will find the perfect match able to mend a broken heart.

\section{Acknowledgements}

We wish to thank Professors Tatsuya Shimizu, Masayuki Yamato, Jose Manuel Garcia Verdugo, Teruo Okano, and Marjo Yliperttula, who gave us scientific support and assistance.

\section{Financial support}

This work was supported by grants from the Academy of Finland (C.E.L. research fellow numbers 273689, 266486 and grant number 278153), (A.S.G., grant number 276371).

\section{Conflict of interest}

\section{None}

\section{Authors contributions}


A. S. G., J. O., V. M., C. G., A. V., E. S. acquisition of information and interpretation; (b) A. S. G., J. O., V. M., A. V., C. E. L. drafting the article; A. S. G., J. O., C. E. L. revising it critically; C. E. L. final approval of the version to be published.

\section{References}

1. World Health Organization (WHO) (2014) World Health Statistics 2014. Geneva, Switzerland

2. Go, A.S., et al. (2013) Heart disease and stroke statistics - 2013 update: A report from the American heart association. Circulation 127(1), e6-e245

3. Nkomo, V.T., et al. (2006) Burden of valvular heart diseases: a population-based study. Lancet 368, 1005-1011

4. Hoerstrup, S.P., et al. (2000) Functional living trileaflet heart valves grown in vitro. Circulation 102(19 Suppl 3), III44-49

5. Sewell-Loftin, M.K., et al. (2011) EMTinducing biomaterials for heart valve engineering: Taking cues from developmental biology. J Cardiovasc Transl R 4(5), 658-671

6. Groth, C.G. and Chapman, J.R. (2006) The Global Alliance for Transplantation. Transpl P 38, 356357

$7 . \quad 2012)$ European Markets for Heart Valve Repair and Replacement Products. In (Greenfield, P. ed.), p. 340. MedTech Insight, New York

8. Loffredo, C. (2000) Epidemiology of cardiovascular malformations: prevalence and risk factors. Am J Med Genet 97, 319-325

9. Kalter, H.(2007) Congenital Cardiovascular Malformations. In Mortality and Maldevelopment, pp. 57-59. Springer Netherlands, Netherlands

10. Rajani, B., Mee, R.B. and Ratliff, N.B. (1998) Evidence for rejection of homograft cardiac valves in infants. J Thorac Cardiovasc Surg 115(1), 111-117

11. Vahanian, A. and Alfieri, O. (2012) Guidelines on the management of valvular heart disease (version 2012). Eur Heart J 33, 2451-2496

12. Hasan, A., et al. (2014) Biomechanical properties of native and tissue engineered heart valve constructs. J Biomech 47(9), 1949-1963

13. Murphy, S.V. and Atala, A. (2012) Organ engineering - combining stem cells, biomaterials, and bioreactors to produce bioengineered organs for transplantation. Bioessays 35, 163-172

14. Mayer, J.E. (2014) ATE 605 - Autologous tissue-engineered hear valve replacement. Presented at the Scientific Sessions 2014 Chicago, Illinois),

15. Bonow, R.O., et al. (2006) ACC/AHA 2006 Guidelines for the Management of Patients With Valvular Heart Disease: A Report of the American College of Cardiology/American Heart Association
Task Force on Practice Guidelines. Circulation 114, e84-e231

16. Ross, D.N. (1962) Homograft replacement of the aortic valve. The Lancet 280(7254), 487

17. El-Hamamsy, I., et al. Long-term outcomes after autograft versus homograft aortic root replacement in adults with aortic valve disease: a randomised controlled trial. The Lancet 376(9740), 524-531

18. Jana, S., et al. (2014) Scaffolds for tissue engineering of cardiac valves. Acta Biomater 10(7), 2877-2893

19. Stradins, P., et al. (2004) Comparison of biomechanical and structural properties between human aortic and pulmonary valve. Eur J Cardiothorac Surg 26(3), 634-639

20. Rabkin-Aikawa, E., et al. (2004) Dynamic and reversible changes of interstitial cell phenotype during remodeling of cardiac valves. J Heart Valve Dis. 13(5), 841-847

21. Liu, A.C., Joag, V.R. and Gotlieb, A.I. (2007) The emerging role of valve interstitial cell phenotypes in regulating heart valve pathobiology. Am J Pathol 171(5), 1407-1418

22. Markwald, R.R., Fitzharris, T.P. and Manasek, F.J. (1977) Structural development of endocardial cushions. Am J Anat 148(1), 85-119

23. Yoshida, R., et al. (1995) Comb-type grafted hydrogels with rapid deswelling response to temperature changes. Nature 374(6519), 240-242

24. Desmouliere, A. and Gabbiani, G. (1995) Myofibroblast differentiation during fibrosis. Exp Nephrol 3(2), 134-139

25. Tamura, K., et al. (2000) Wound healing in the mitral valve. J Heart Valve Dis 9(1), 53-63

26. Paruchuri, S., et al. (2006) Human pulmonary valve progenitor cells exhibit endothelial/mesenchymal plasticity in response to vascular endothelial growth factor-A and transforming growth factor-beta2. Circ Res 99(8), 861-869

27. Sata, M. (2006) Role of circulating vascular progenitors in angiogenesis, vascular healing, and pulmonary hypertension: lessons from animal models. Arterioscler Thromb Vasc Biol 26(5), 1008-1014

28. Visconti, R.P., et al. (2006) An in vivo analysis of hematopoietic stem cell potential: hematopoietic origin of cardiac valve interstitial cells. Circ Res 98(5), 690-696

29. Rajamannan, N.M., et al. (2003) Human aortic valve calcification is associated with an osteoblast phenotype. Circulation 107(17), 2181-2184

30. Sacks, M.S. and Yoganathan, A.P. (2007) Heart valve function: a biomechanical perspective. Philos Trans R Soc Lond B Biol Sci 362(1484), 1369-1391

31. Johnson, C.M., Hanson, M.N. and Helgeson, S.C. (1987) Porcine cardiac valvular subendothelial cells in culture - cell isolation and growthcharacteristics. J Mol Cell Cardiol 19(12), 1185-1193 
32. Filip, D.A., Radu, A. and Simionescu, M. (1986) Interstitial cells of the heart valves possess characteristics similar to smooth muscle cells. Circ Res 59(3), 310-320

33. Hinton, R.J., et al. (2006) Extracellular matrix remodeling and organization in developing and diseased aortic valves. Circ Res 98, 1431-1438

34. Taylor, P.M., et al. (2003) The cardiac valve interstitial cell. Int J Biochem Cell Biol 35, 113-118

35. Butcher, J.T., et al. (2004) Unique morphology and focal adhesion development of valvular endothelial cells in static and fluid flow environments. Arterioscler Thromb Vasc Biol 24, 1429-1434

36. Butcher, J.T. and Nerem, R.M. (2007) Valvular endothelial cells and the mechanoregulation of valvular pathology. Phil. Trans. R. Soc. B 362, 1445-1457

37. Poggianti, E., et al. (2003) Aortic valve sclerosis is associated with systemic endothelial dysfunction. J Am Coll Cardiol 41(1), 136-141

38. Baaijens, F., Bouten, C. and Driessen, N. (2010) Modeling collagen remodeling. J Biomech 43(1), $166 \mathrm{e} 175$

39. Vesely, I. and Noseworthy, R. (1992) Micromechanics of the fibrosa and the ventricularis in aortic valve leaflets. J Biomech 25, 101-113

40. Schoen, F.J. (2008) Evolving concepts of cardiac valve dynamics : The continuum of development, functional structure, pathobiology, and tissue engineering. Circulation 118, 1864-1880

41. Lovekamp, J.J., et al. (2006) Stability and function of glycosaminoglycans in porcine bioprosthetic heart valves. Biomaterials 27(8), 1507-1518

42. Cigliano, A., et al. (2011) Fine structure of glycosaminoglycans from fresh and decellularized porcine cardiac valves and pericardium. Bioorg Chem, $1-10$

43. Walker, G.A., et al. (2004) Valvular myofibroblast activation by transforming growth factor$\beta$ : implications for pathological extracellular matrix remodeling in heart valve disease. Circ Res 95, 253-260 44. Yacoub, M., et al. (1995) Fourteen-year experience with homovital homografts for aortic valve replacement. J Thorac Cardiovasc Surg 110(1), 186-194 45. Harken, D.E., et al. (1960) Partial and complete prostheses in aortic insufficiency. $\mathrm{J}$ Thorac Cardiovasc Surg 40(

), 744-762

46. Starr, A. and Edwards, M.L. (1961) Mitral replacement: clinical experience with a ball-valve prosthesis. Ann Surg 154 4(726-40)

47. Mol, A., et al. (2009) Tissue engineering of heart valves: advances and current challenges. Expert Rev Med Devices 6(3), 259-275

48. Hammermeister, K., et al. (2000) Outcomes 15 years after valve replacement with a mechanical versus a bioprosthetic valve: final report of the Veterans Affairs randomized trial. J Am Coll Cardiol 36(4), 1152-1158
49. Klepetko, W., et al. (1999) Leaflet fracture in Edwards-Duromedics bileaflet valves. J Thorac Cardiovasc Surg 97(1), 90-94

50. Sacks, M.S. and Schoen, F.J. (2002) Collagen fiber disruption occurs independent of calcification in clinically explanted bioprosthetic heart valves. J Biomed Mater Res 62(3), 359-371

51. Jamieson, W.R., et al. (2005) Performance of bioprostheses and mechanical prostheses assessed by composites of valve-related complications to 15 years after mitral valve replacement. J Thorac Cardiovasc Surg 129(6), 1301-1308

52. van den Heever, J.J., et al. (2013) The effect of different treatment modalities on the calcification potential and cross-linking stability of bovine pericardium. Cell and Tissue Banking 14(1), 53-63

53. Mathapati, S., et al. (2013) Biomimetic acellular detoxified glutaraldehyde cross-linked bovine pericardium for tissue engineering. Mater Sci Eng C Mater Biol Appl 33(3), 1561-1572

54. Dohmen, P.M. (2012) Clinical results of implanted tissue engineered heart valves. HSR Proc Intensive Care Cardiovasc Anesth 4(4), 225-231

55. Barratt-Boyes, B.G., et al. (1969) Aortic homograft valve replacement. A long-term follow-up of an initial series of 101 patients. Circulation 40(6), 763775

56. O'Brien, M.F., et al. (2001) The homograft aortic valve: a 29 -year, $99.3 \%$ follow up of 1,022 valve replacements. J Heart Valve Dis 10(3), 334-344

57. O'Brien, M.F., et al. (1991) Allograft aortic valve replacement: long-term comparative clinical analysis of the viable cryopreserved and antibiotic 4 degrees C stored valves. J Card Surg. 6(4 Suppl), 534543

58. Hilbert, S.L., et al. (1999) Allograft heart valves: the role of apoptosis-mediated cell loss. J Thorac Cardiovasc Surg 117(3), 454-462

59. Koolbergen, D.R., et al. (2002) The pathology of fresh and cryopreserved homograft heart valves: An analysis of forty explanted homograft valves. J Thorac Cardiovasc Surg 124(4), 689-697

60. Hawkins, J.A., et al. (2003) Immunogenicity of decellularized cryopreserved allografts in pediatric cardiac surgery: comparison with standard cryopreserved allografts. J Thorac Cardiovasc Surg 126(1), 247-252; discussion 252-243

61. Hogan, P., et al. (1996) Human aortic valve allografts elicit a donor-specific immune response. J Thorac Cardiovasc Surg 112(5), 1260-1267

62. den Hamer, I., et al. (1997) HLA antibodies specific for cryopreserved heart valve "homografts" in children. J Thorac Cardiovasc Surg 113(2), 417-419

63. Christenson, J.T., et al. (2004) Blood group incompatibility and accelerated homograft fibrocalcifications. J Thorac Cardiovasc Surg 127(1), 242-250 
64. Jashari, R., et al. (2004) Is ABO group incompatibility really the reason of accelerated failure of cryopreserved allografts in very young patients? Echography assessment of the European Homograft Bank (EHB) cryopreserved allografts used for reconstruction of the right ventricular outflow tract*. Cell and Tissue Banking 5(4), 253-259

65. Shaddy, R.E. and Hawkins, J.A. (2002) Immunology and failure of valved allografts in children. Ann Thorac Surg 74(4), 1271-1275

66. Johnson, D.L., et al. (1998) Effect of antibiotic pretreatment on immunogenicity of human heart valves and component cells. Ann Thorac Surg 66(6 Suppl), S221-224

67. Koolbergen, D.R., et al. (1998) Tissue chimerism in human cryopreserved homograft valve explants demonstrated by in situ hybridization. Ann Thorac Surg 66(6 Suppl), S225-232

68. Mitchell, R.N., Jonas, R.A. and Schoen, F.J. (1998) Pathology of explanted cryopreserved allograft heart valves: comparison with aortic valves from orthotopic heart transplants. J Thorac Cardiovasc Surg 115(1), 118-127

69. Bechtel, J.F., et al. (2001) Does histocompatibility affect homograft valve function after the Ross procedure? Circulation 104(12 Suppl 1), I2528

70. Troost, E., et al. (2007) Homograft survival after tetralogy of Fallot repair: determinants of accelerated homograft degeneration. Eur Heart J 28(20), 2503-2509

71. Lu, J.-H., et al. (1998) Metabolic detriment in donor heart valves induced by ischemia and cryopreservation. Ann Thorac Surg 65(1), 24-27

72. Jashari, R., et al. (2010) European homograft bank: Twenty years of cardiovascular tissue banking and collaboration with transplant coordination in Europe. Transplant Proc 42(1), 183-189

73. Herberts, C.A., et al. (2015) Results from a horizon scan on risks associated with transplantation of human organs, tissues and cells: from donor to patient. Cell and Tissue Banking 16(1), 1-17

74. van Wijk, M., van den Bogaerdt, A. and Bokhorst, A. (2013) Risk factors for rejection for morphological reasons of heart valves for transplantation. Cell and Tissue Banking 14(1), 125-132 75. Segur, J.M., et al. (2000) The procurement team as a factor of bone allograft contamination. Cell and Tissue Banking 1(2), 117-119

76. Caselli-Fernández, L.M. and Terkola, R. (2006) Clean room environment, personnel, quality assurance and their monitoring. Eur J Hosp Pharm Pract 12, 29-34

77. Mirabet, V., et al. (2012) Use of liquid nitrogen during storage in a cell and tissue bank: Contamination risk and effect on the detectability of potential viral contaminants. Cryobiology 64(2), 121-123
78. Heng, W.L., et al. (2013) International heart valve bank survey: a review of processing practices and activity outcomes. J Transplant 2013, 163150

79. Fischlein, T., et al. (1994) Integrity and viability of homograft valves. Eur J Cardiothorac Surg 8(8), 425430

80. Gall, K.L., et al. (1998) Allograft heart valve viability and valve-processing variables. Ann Thorac Surg 65(4), 1032-1038

81. Mirabet, V., et al. (2008) Long-term storage in liquid nitrogen does not affect cell viability in cardiac valve allografts. Cryobiology 57(2), 113-121

82. Messier, R.H., Jr., et al. (1999) Interstitial cellular and matrix restoration of cardiac valves after cryopreservation. J Thorac Cardiovasc Surg 118(1), 3639

83. Clarke, D.R. and Bishop, D.A. (1993) Allograft degeneration in infant pulmonary valve allograft recipients. Eur J Cardiothorac Surg 7(7), 365-370

84. Harken, D.E. (1989) Heart valves: ten commandments and still counting. Ann Thorac Surg 48(3 Suppl), S18-19

85. Chang, C.H., et al. (2013) Human acellular cartilage matrix powders as a biological scaffold for cartilage tissue engineering with synovium-derived mesenchymal stem cells. J Biomed Mater Res A 102(7), 2248-2257

86. Sutherland, F.W., et al. (2005) From stem cells to viable autologous semilunar heart valve. Circulation 111(21), 2783-2791

87. Deme, S., et al. (2006) On-board TLD measurements on MIR and ISS. Radiat Prot Dosimetry 120(1-4), 438-441

88. Khademhosseini, A., et al. (2006) Microscale technologies for tissue engineering and biology. Proc Natl Acad Sci U S A 103(8), 2480-2487

89. Driessen, N.J.B., et al. (2007) Modeling the mechanics of tissue-engineered human heart valve leaflets. J Biomech 40(2), 325-334

90. Legg, M., Mathews, E. and Pelzer, R. (2012) The design and development of a stented tissue mitral and aortic heart valve replacement for human implantation. Cardiovasc J Afr 23(3), 126-130

91. Cebotari, S., et al. (2002) Construction of autologous human heart valves based on an acellular allograft matrix. Circulation 106(12 Suppl 1), I63-I68

92. Gilbert, T.W., Sellaro, T.L. and Badylak, S.F. (2006) Decellularization of tissues and organs. Biomaterials 27(19), 3675-3683

93. Simon, P., et al. (2003) Early failure of the tissue engineered porcine heart valve SYNERGRAFT in pediatric patients. Eur J Cardiothorac Surg 23(6), 10021006; discussion 1006

94. Emmert, M.Y., et al. (2012) Stem cell-based transcatheter aortic valve implantation: first experiences in a pre-clinical model. JACC Cardiovasc Interv 5(8), 874-883 
Expert Reviews in Molecular Medicine

95. Cheung, A., et al. (2014) Short-Term Results of Transapical Transcatheter Mitral Valve Implantation for Mitral Regurgitation. J Am Coll Cardiol 64(17), 1814-1819

96. Sadowski, J., et al. (2014) Aortic valve replacement with a novel anti-calcification technology platform. Kardiol Pol

97. Bobylev, D., et al. (2014) Semilunar Valve Replacement With Decellularized Homograft After Damus-Kaye-Stansel Anastomosis and Fontan Procedure. Ann Thorac Surg 97(5), 1792-1795

98. Iop, L., et al. (2009) The influence of heart valve leaflet matrix characteristics on the interaction between human mesenchymal stem cells and decellularized scaffolds. Biomaterials 30(25), 41044116

99. Ye, X., et al. (2012) Polyelectrolyte multilayer film on decellularized porcine aortic valve can reduce the adhesion of blood cells without affecting the growth of human circulating progenitor cells. Acta Biomater 8(3), 1057-1067

100. Ye, X., et al. (2013) The effect of HeparinVEGF multilayer on the biocompatibility of decellularized aortic valve with platelet and endothelial progenitor cells. PLoS One 8(1), e54622

101. Francoise, M., et al. (2012) Toward engineering functional organ modules by additive manufacturing. Biofabrication 4(2), 022001

102. Weber, B., Zeisberger, S.M. and Hoerstrup, S.P. (2011) Prenatally harvested cells for cardiovascular tissue engineering: fabrication of autologous implants prior to birth. Placenta 32 Suppl 4, S316-319

103. Jordan, J.E., et al. (2012) Bioengineered selfseeding heart valves. J Thorac Cardiovasc Surg 143(1), 201-208

104. Zund, G., et al. (1997) The in vitro construction of a tissue engineered bioprosthetic heart valve. European Journal of Cardio-thoracic Surgery 11(3), 493-497

105. Sodian, R., et al. (2000) Fabrication of a trileaflet heart valve scaffold from a polyhydroxyalkanoate biopolyester for use in tissue engineering. Tissue Eng 6(2), 183-188

106. Hoerstrup, S.P., et al. (2002) Tissue engineering of functional trileaflet heart valves from human marrow stromal cells. Circulation 106(12 Suppl 1), I143-150

107. Dan, L. and Younan, X. (2004) Electrospinning of nanofibers: Reinventing the wheel? Adv Mater 16(14), 1151-1170

108. Amoroso, N.J., et al. (2012) Microstructural manipulation of electrospun scaffolds for specific bending stiffness for heart valve tissue engineering. Acta Biomater 8(12), 4268-4277

109. Kalfa, D., et al. (2010) A polydioxanone electrospun valved patch to replace the right ventricular outflow tract in a growing lamb model. Biomaterials 31(14), 4056-4063
110. Duan, B., et al. (2013) Three-dimensional printed trileaflet valve conduits using biological hydrogels and human valve interstitial cells. Acta Biomater 10(5), 1836-1846

111. Tedder, M.E., et al. (2011) Assembly and testing of stem cell-seeded layered collagen constructs for heart valve tissue engineering. Tissue Eng Part A 17(1-2), 25-36

112. Hockaday, L.A., et al. (2012) Rapid 3D printing of anatomically accurate and mechanically heterogeneous aortic valve hydrogel scaffolds. Biofabrication 4(3), 035005

113. Shinoka, T., et al. (1995) Tissue engineering heart valves: valve leaflet replacement study in a lamb model. Ann Thorac Surg 60(6 Suppl), S513-516

114. Shinoka, T., et al. (1996) Tissue-engineered heart valves. Autologous valve leaflet replacement study in a lamb model. Circulation 94(9 Suppl), II164-168

115. Dvorin, E.L., et al. (2003) Quantitative evaluation of endothelial progenitors and cardiac valve endothelial cells: proliferation and differentiation on poly-glycolic acid/poly-4-hydroxybutyrate scaffold in response to vascular endothelial growth factor and transforming growth factor beta1. Tissue Eng 9(3), 487493

116. Sodian, R., et al. (2000) Evaluation of biodegradable, three-dimensional matrices for tissue engineering of heart valves. ASAIO J 46(1), 107-110

117. Bernacca, G.M., et al. (1997) Polyurethane heart valves: fatigue failure, calcification, and polyurethane structure. J Biomed Mater Res 34(3), 371379

118. Daebritz, S.H., et al. (2004) New flexible polymeric heart valve prostheses for the mitral and aortic positions. Heart Surg Forum 7(5), E525-532

119. Brugmans, M.M., et al. (2013) Poly-epsiloncaprolactone scaffold and reduced in vitro cell culture: beneficial effect on compaction and improved valvular tissue formation. J Tissue Eng Regen Med (online)

120. Sant, S. and Khademhosseini, A. (2010) Fabrication and characterization of tough elastomeric fibrous scaffolds for tissue engineering applications. Conf Proc IEEE Eng Med Biol Soc 2010, 3546-3548

121. Mitchell, S.L. and Niklason, L.E. (2003) Requirements for growing tissue-engineered vascular grafts. Cardiovascular Pathology 12(2), 59-64

122. Emani, S., Mayer, J.E., Jr. and Emani, S.M. (2011) Gene regulation of extracellular matrix remodeling in human bone marrow stem cell-seeded tissue-engineered grafts. Tissue Eng Part A 17(19-20), 2379-2388

123. Engelmayr, G.C., Jr., et al. (2006) Cyclic flexure and laminar flow synergistically accelerate mesenchymal stem cell-mediated engineered tissue formation: Implications for engineered heart valve tissues. Biomaterials 27(36), 6083-6095 


\section{Expert Reviews in Molecular Medicine}

124. Gottlieb, D., et al. (2010) In vivo monitoring of function of autologous engineered pulmonary valve. J Thorac Cardiovasc Surg 139(3), 723-731

125. Stock, U.A., et al. (2000) Tissue-engineered valved conduits in the pulmonary circulation. J Thorac Cardiovasc Surg 119(4), 732-740

126. Wu, W., et al. (2011) Artificial niche combining elastomeric substrate and platelets guides vascular differentiation of bone marrow mononuclear cells. Tissue Eng Part A 17(15-16), 1979-1992

127. Badylak, S.F. (2002) The extracellular matrix as a scaffold for tissue reconstruction. Semin Cell Dev Biol 13(5), 377-383

128. Grant, C.A., Twigg, P.C. and Tobin, D.J. (2012) Static and dynamic nanomechanical properties of human skin tissue using atomic force microscopy: Effect of scarring in the upper dermis. Acta Biomater 8(11), 4123-4129

129. Sommer, G., et al. (2013) Multiaxial mechanical response and constitutive modeling of esophageal tissues: impact on esophageal tissue engineering. Acta Biomater 9(12), 9379-9391

130. Anderson, D.J. and Hinds, M. (2011) Endothelial cell micropatterning: methods, effects, and applications. Ann Biomed Eng 39(9), 2329-2345

131. Robinson, P.S., et al. (2008) Functional tissueengineered valves from cell-remodeled fibrin with commissural alignment of cell-produced collagen. Tissue Engineering Part A 14(1), 83-95

132. Flanagan, T.C., et al. (2009) In vivo remodeling and structural characterization of fibrin-based tissueengineered heart valves in the adult sheep model. Tissue Eng Part A 15(10), 2965-2976

133. Wang, B., et al. (2013) Myocardial scaffoldbased cardiac tissue engineering: application of coordinated mechanical and electrical stimulations. Langmuir 29(35), 11109-11117

134. Hong, H., et al. (2009) Fabrication of a novel hybrid heart valve leaflet for tissue engineering: an in vitro study. Artif Organs 33(7), 554-558

135. Hockaday, L.A., et al. (2014) 3D-Printed Hydrogel Technologies for Tissue-Engineered Heart Valves. 3D Printing and Additive Manufacturing 1(3), $122-136$

136. Xu, T., et al. (2013) Complex heterogeneous tissue constructs containing multiple cell types prepared by inkjet printing technology. Biomaterials 34(1), 130139

137. Vunjak-Novakovic, G., et al. (2010) Challenges in Cardiac Tissue Engineering. Tissue Engineering Part B: Reviews 16(2), 169-187

138. Dreger, S.A., et al. (2006) Potential for synthesis and degradation of extracellular matrix proteins by valve interstitial cells seeded onto collagen scaffolds. Tissue Eng 12(9), 2533-2540

139. Ye, Q., et al. (2000) Scaffold precoating with human autologous extracellular matrix for improved cell attachment in cardiovascular tissue engineering. ASAIO J 46(6), 730-733

140. Ye, Q., et al. (2000) Fibrin gel as a three dimensional matrix in cardiovascular tissue engineering. Eur J Cardiothorac Surg 17(5), 587-591

141. Hoerstrup, S.P., et al. (2002) A new approach to completely autologous cardiovascular tissue in humans. ASAIO J 48(3), 234-238

142. Ye, Q., et al. (2000) Tissue engineering in cardiovascular surgery: new approach to develop completely human autologous tissue. Eur J Cardiothorac Surg 17(4), 449-454

143. Mol, A., et al. (2003) The relevance of large strains in functional tissue engineering of heart valves. Thorac Cardiovasc Surg 51(2), 78-83

144. Schnell, A.M., et al. (2001) Optimal cell source for cardiovascular tissue engineering: venous vs. aortic human myofibroblasts. Thorac Cardiovasc Surg 49(4), 221-225

145. Sodian, R., et al. (2002) Application of stereolithography for scaffold fabrication for tissue engineered heart valves. ASAIO J 48(1), 12-16

146. Steinhoff, G., et al. (2000) Tissue engineering of pulmonary heart valves on allogenic acellular matrix conduits: in vivo restoration of valve tissue. Circulation 102(19 Suppl 3), III50-55

147. Dohmen, P.M., et al. (2002) Ross operation with a tissue-engineered heart valve. Ann Thorac Surg 74(5), 1438-1442

148. Dohmen, P.M., et al. (2011) Ten years of clinical results with a tissue-engineered pulmonary valve. Ann Thorac Surg 92(4), 1308-1314

149. Dohmen, P.M., et al. (2007) Mid-term clinical results using a tissue-engineered pulmonary valve to reconstruct the right ventricular outflow tract during the Ross procedure. Ann Thorac Surg 84(3), 729-736

150. Weber, B., Emmert, M.Y. and Hoerstrup, S.P. (2012) Stem cells for heart valve regeneration. Swiss Med Wkly 142, w 13622

151. Asahara, T., et al. (1997) Isolation of putative progenitor endothelial cells for angiogenesis. Science 275(5302), 964-967

152. Yoder, M.C. (2012) Human endothelial progenitor cells. Cold Spring Harb Perspect Med 2(7), a006692

153. Matsumoto, Y., et al. (2009) Reduced number and function of endothelial progenitor cells in patients with aortic valve stenosis: a novel concept for valvular endothelial cell repair. Eur Heart J 30(3), 346-355

154. Redondo, S., et al. (2012) Decreased presurgical CD34+/CD144+ cell number in patients undergoing coronary artery bypass grafting compared to coronary artery disease-free valvular patients. J Cardiothorac Surg 7(1), 2

155. Shimoni, S., et al. (2013) Circulating progenitor and apoptotic progenitor cells in patients with aortic regurgitation. Circ J 77(3), 764-771 
156. Smadja, D.M., et al. (2009) Endothelial progenitor cells are selectively mobilised immediately after coronary artery bypass grafting or valve surgery. Thromb Haemost 101(5), 983-985

157. Vaturi, M., et al. (2011) Circulating endothelial progenitor cells in patients with dysfunctional versus normally functioning congenitally bicuspid aortic valves. Am J Cardiol 108(2), 272-276

158. Sales, V.L., et al. (2007) Protein precoating of elastomeric tissue-engineering scaffolds increased cellularity, enhanced extracellular matrix protein production, and differentially regulated the phenotypes of circulating endothelial progenitor cells. Circulation 116(11 Suppl), I55-63

159. Sales, V.L., et al. (2010) Endothelial progenitor cells as a sole source for ex vivo seeding of tissueengineered heart valves. Tissue Eng Part A 16(1), 257267

160. Bischoff, J. and Aikawa, E. (2011) Progenitor cells confer plasticity to cardiac valve endothelium. J Cardiovasc Transl Res 4(6), 710-719

161. Cebotari, S., et al. (2006) Clinical application of tissue engineered human heart valves using autologous progenitor cells. Circulation 114(1 Suppl), I132-137

162. Colazzo, F., et al. (2011) Extracellular matrix production by adipose-derived stem cells: implications for heart valve tissue engineering. Biomaterials 32(1), $119-127$

163. Delaine-Smith, R.M. and Reilly, G.C. (2012) Mesenchymal stem cell responses to mechanical stimuli. Muscles Ligaments Tendons J 2(3), 169-180

164. O'Neill, J.D., et al. (2013) Decellularization of human and porcine lung tissues for pulmonary tissue engineering. Ann Thorac Surg 96(3), 1046-1055

165. Latif, N., et al. (2007) Characterization of structural and signaling molecules by human valve interstitial cells and comparison to human mesenchymal stem cells. J Heart Valve Dis 16(1), 56-66

166. Hajdu, Z., et al. (2011) Recruitment of bone marrow-derived valve interstitial cells is a normal homeostatic process. J Mol Cell Cardiol 51(6), 955-965

167. Perry, T.E., et al. (2003) Thoracic Surgery Directors Association Award. Bone marrow as a cell source for tissue engineering heart valves. Ann Thorac Surg 75(3), 761-767; discussion 767

168. Perry, T.E. and Roth, S.J. (2003) Cardiovascular tissue engineering: constructing living tissue cardiac valves and blood vessels using bone marrow, umbilical cord blood, and peripheral blood cells. J Cardiovasc Nurs 18(1), 30-37

169. Zhang, J., et al. (2006) Engineering of vascular grafts with genetically modified bone marrow mesenchymal stem cells on poly (propylene carbonate) graft. Artif Organs 30(12), 898-905

170. Kaminski, A., et al. (2011) Autologous valve replacement-CD133+ stem cell-plus-fibrin compositebased sprayed cell seeding for intraoperative heart valve tissue engineering. Tissue Eng Part C Methods 17(3), 299-309

171. Bin, F., et al. (2006) Construction of tissueengineered homograft bioprosthetic heart valves in vitro. ASAIO J 52(3), 303-309

172. Vincentelli, A., et al. (2007) In vivo autologous recellularization of a tissue-engineered heart valve: are bone marrow mesenchymal stem cells the best candidates? J Thorac Cardiovasc Surg 134(2), 424-432

173. Xin, Y., et al. (2010) Aging adversely impacts biological properties of human bone marrow-derived mesenchymal stem cells: implications for tissue engineering heart valve construction. Artif Organs 34(3), 215-222

174. Huang, W., et al. (2013) Fn14 promotes differentiation of human mesenchymal stem cells into heart valvular interstitial cells by phenotypic characterization. J Cell Physiol 229(5), 580-587

175. Lin, W.H. and Tsai, W.B. (2013) In situ UVcrosslinking gelatin electrospun fibers for tissue engineering applications. Biofabrication 5(3), 035008

176. Ramaswamy, S., et al. (2010) The role of organ level conditioning on the promotion of engineered heart valve tissue development in-vitro using mesenchymal stem cells. Biomaterials 31(6), 1114-1125

177. Leskela, H.V., et al. (2006) Calcification and cellularity in human aortic heart valve tissue determine the differentiation of bone-marrow-derived cells. J Mol Cell Cardiol 41(4), 642-649

178. Boldt, J., et al. (2013) Percutaneous tissueengineered pulmonary valved stent implantation: comparison of bone marrow-derived CD133+-cells and cells obtained from carotid artery. Tissue Eng Part C Methods 19(5), 363-374

179. Kim, S.S., et al. (2006) Tissue engineering of heart valves by recellularization of glutaraldehyde-fixed porcine valves using bone marrow-derived cells. Exp Mol Med 38(3), 273-283

180. Weber, B., et al. (2011) Injectable living marrow stromal cell-based autologous tissue engineered heart valves: first experiences with a one-step intervention in primates. Eur Heart J 32(22), 2830-2840 181. Hibino, N., et al. (2011) A critical role for macrophages in neovessel formation and the development of stenosis in tissue-engineered vascular grafts. FASEB J 25(12), 4253-4263

182. Fraser, J., et al.(2008) Adipose-Derived Stem Cells. In Mesenchymal Stem Cells (Prockop, D., Bunnell, B. and Phinney, D. eds.), pp. 59-67. Humana Press,

183. Kuhbier, J., et al.(2010) Isolation, Characterization, Differentiation, and Application of Adipose-Derived Stem Cells. In Bioreactor Systems for Tissue Engineering II (Kasper, C., van Griensven, M. and Pörtner, R. eds.), pp. 55-105. Springer Berlin Heidelberg,

184. Kern, S., et al. (2006) Comparative analysis of mesenchymal stem cells from bone marrow, umbilical 
cord blood, or adipose tissue. Stem Cells 24(5), 12941301

185. Hannachi, I.E., Yamato, M. and Okano, T. (2009) Cell sheet technology and cell patterning for biofabrication. Biofabrication 1(2), 022002

186. DiMuzio, P. and Tulenko, T. (2007) Tissue engineering applications to vascular bypass graft development: the use of adipose-derived stem cells. J Vasc Surg 45( Suppl A), A99-103

187. Escobedo-Lucea, C., et al. (2013) A Xenogeneic-Free Protocol for Isolation and Expansion of Human Adipose Stem Cells for Clinical Uses. PLoS One 8(7), e67870

188. Colazzo, F., et al. (2010) Induction of mesenchymal to endothelial transformation of adiposederived stem cells. J Heart Valve Dis 19(6), 736-744

189. Fischer, L.J., et al. (2009) Endothelial differentiation of adipose-derived stem cells: effects of endothelial cell growth supplement and shear force. J Surg Res 152(1), 157-166

190. Prusa, A.R., et al. (2003) Oct-4-expressing cells in human amniotic fluid: a new source for stem cell research? Hum Reprod 18(7), 1489-1493

191. Benavides, O.M., et al. (2012) Evaluation of endothelial cells differentiated from amniotic fluidderived stem cells. Tissue Eng Part A 18(11-12), 11231131

192. Moschidou, D., et al. (2013) Molecular signature of human amniotic fluid stem cells during fetal development. Curr Stem Cell Res Ther 8(1), 73-81 193. Moschidou, D., et al. (2012) Valproic acid confers functional pluripotency to human amniotic fluid stem cells in a transgene-free approach. Mol Ther 20(10), 1953-1967

194. Moschidou, D., et al. (2013) Human midtrimester amniotic fluid stem cells cultured under embryonic stem cell conditions with valproic acid acquire pluripotent characteristics. Stem Cells Dev 22(3), 444-458

195. Schmidt, D., et al. (2007) Prenatally fabricated autologous human living heart valves based on amniotic fluid derived progenitor cells as single cell source. Circulation 116(11 Suppl), I64-70

196. Schmidt, D., et al. (2006) Living autologous heart valves engineered from human prenatally harvested progenitors. Circulation 114(1 Suppl), I125131

197. Weber, B., et al. (2012) Prenatally engineered autologous amniotic fluid stem cell-based heart valves in the fetal circulation. Biomaterials 33(16), 4031-4043

198. Schmidt, D. and Hoerstrup, S.P. (2006) Tissue engineered heart valves based on human cells. Swiss Med Wkly 136(39-40), 618-623

199. Weymann, A., et al. (2013) Reendothelialization of human heart valve neoscaffolds using umbilical cord-derived endothelial cells. Circ J 77(1), 207-216
200. Sha, J.M., et al. (2010) In-vitro seeding of human umbilical cord vein endothelial cells on hydroxyapatite for mechanical heart valve applications. J Heart Valve Dis 19(4), 506-512

201. Tu, Q., et al. (2010) Improved endothelialization of titanium vascular implants by extracellular matrix secreted from endothelial cells. Tissue Eng Part A 16(12), 3635-3645

202. Schmidt, D., et al. (2005) Living patches engineered from human umbilical cord derived fibroblasts and endothelial progenitor cells. Eur J Cardiothorac Surg 27(5), 795-800

203. Schmidt, D., et al. (2006) Engineered living blood vessels: functional endothelia generated from human umbilical cord-derived progenitors. Ann Thorac Surg 82(4), 1465-1471; discussion 1471

204. Takahashi, K., et al. (2007) Induction of pluripotent stem cells from adult human fibroblasts by defined factors. Cell 131(5), 861-872

205. Lu, T.Y., et al. (2013) Repopulation of decellularized mouse heart with human induced pluripotent stem cell-derived cardiovascular progenitor cells. Nat Commun 4, 2307

206. Rajamannan, N.M., et al. (2011) Calcific aortic valve disease: not simply a degenerative process: A review and agenda for research from the National Heart and Lung and Blood Institute Aortic Stenosis Working Group. Executive summary: Calcific aortic valve disease-2011 update. Circulation 124(16), 1783-1791

207. Yoshioka, M., et al. (2006) Chondromodulin-I maintains cardiac valvular function by preventing angiogenesis. Nat Med 12(10), 1151-1159

208. Dohmen, P.M., et al. (2002) Tissue Engineering of an Auto-Xenograft Pulmonary Heart Valve. Asian Cardiovascular and Thoracic Annals 10(1), 25-30

209. Banbury, M.K., et al. (2002) Hemodynamic stability during 17 years of the carpentier-edwards aortic pericardial bioprosthesis. Ann Thorac Surg 73(5), 14601465

210. Benhameid, O., et al. (2008) CarboMedics Mitroflow Pericardial Aortic Bioprosthesis Performance in Patients Aged 60 Years and Older after 15 Years. Thorac Cardiovasc Surg 56(04), 195-199

211. Brown, J.W., et al. (2010) Performance of the CryoValve* SG human decellularized pulmonary valve in 342 patients relative to the conventional CryoValve at a mean follow-up of four years. J Thorac Cardiovasc Surg 139(2), 339-348

212. Falk, V., et al. (2011) Transapical aortic valve implantation with a self-expanding anatomically oriented valve. Eur Heart J 32(7), 878-887

213. Willson, A.B., et al. (2012) Transcatheter Aortic Valve Replacement With the St. Jude Medical Portico Valve: First-in-Human Experience. J Am Coll Cardiol 60(7), 581-586

214. Altintas, G., et al. (2013) The Sorin Freedom SOLO Stentless Tissue Valve: Early Outcomes after 
Aortic Valve Replacement. Texas Heart Institute Journal 40(1), 50-55

215. Zannis, K., et al. (2014) Aortic valve replacement with the perceval S bioprosthesis: singlecenter experience in 143 patients. J Heart Valve Dis 23(6), 795-802

216. Facchin, M., et al. (2014) The SAPIEN 3 valve: lights and shadows. Minerva Med 105(6), 497-500

217. Yadlapati, A., et al. (2014) Comprehensive hemodynamic performance and frequency of patientprosthesis mismatch of the St. Jude Medical Trifecta bioprosthetic aortic valve. J Heart Valve Dis 23(4), 516523

218. Tudorache, I., et al. (2014) Aortic Valve Replacement with Decellularized Aortic Allografts: First Clinical Results. Circulation 130(Suppl 2), A19959-A19959

219. Cao, Q.-L., et al. (2014) Early clinical experience with a novel self-expanding percutaneous stent-valve in the native right ventricular outflow tract. Catheterization and Cardiovascular Interventions 84(7), 1131-1137

220. Bader, A., et al. (1998) Tissue engineering of heart valves - human endothelial cell seeding of detergent acellularized porcine valves. European Journal of Cardio-thoracic Surgery 14(3), 279-284

221. Zeltinger, J., et al. (2001) Development and characterization of tissue-engineered aortic valves. Tissue Eng 7(1), 9-22

222. Kadner, A., et al. (2002) Human umbilical cord cells: a new cell source for cardiovascular tissue engineering. Ann Thorac Surg 74(4), 1422-1428

223. Sodian, R., et al. (2010) Use of human umbilical cord blood-derived progenitor cells for tissueengineered heart valves. Ann Thorac Surg 89(3), 819828

224. Yamanami, M., et al. (2010) Preparation of invivo tissue-engineered valved conduit with the sinus of Valsalva (type IV biovalve). Journal of Artificial Organs 13(2), 106-112

225. Tedder, M.E., et al. (2010) Assembly and testing of stem cell-seeded layered collagen constructs for heart valve tissue engineering. Tissue Engineering Part A 17(1-2), 25-36

226. Costa, F.D.A.d., et al. (2004) Comparison of cryopreserved homografts and decellularized porcine heterografts implanted in sheep. Artif Organs 28(4), 366-370

227. Schmidt, D., et al. (2010) Minimally-invasive implantation of living tissue engineered heart valves: a comprehensive approach from autologous vascular cells to stem cells. J Am Coll Cardiol 56(6), 510-520

228. Nakayama, Y., et al. (2015) In body tissue engineered aortic valve (Biovalve type VII) architecture based on $3 \mathrm{D}$ printer molding. Journal of Biomedical
Materials Research Part B: Applied Biomaterials 103(1), 1-11 


\section{10. Figures and captions}

2 FIGURE 1. Photographs of human semilunar heart valves: aortic (a) and pulmonary (b).

3 FIGURE 2. Detailed heart valve structure. It is composed of 3 inner layers (ventricularis, 4 spongiosa and fibrosa) and an outer layer formed by valvular endothelial cells (VECs). The three 5 inner layers contain mainly proteoglycans (PGs), glycosaminoglycans (GAGs), collagen type I and 6 type III, elastin, and valvular interstitial cells (VICs). Adapted from (Ref. 206).

7 FIGURE 3. On-going clinical treatments and future possibilities in heart valve tissue

8 engineering (HVTE). The methods to create autologous constructs are a potential alternative to

9 overcome the main drawbacks of traditional bioprosthetic and mechanical valve prostheses

10 (Strategy A). The creation of tissue-engineered heart valves starts from the decellularized or 11 synthetic scaffold, which represents the basic platform where cells proliferate. This can be directly 12 implanted without (Strategy B) or with reseeding cells (Strategies C and D). Different cell types 13 could be candidates for this purpose: vascular endothelial cells (VECs), bone marrow mesenchymal 14 stem cells (BMSCs), induced pluripotent stem cells (iPSCs), chorionic villi-derived mesenchymal 15 progenitor cells, umbilical cord blood (UCB) derived endothelial progenitor cells (EPCs), and 16 adipose-derived stem cells (ASCs), among others. 


\section{10. Tables}

TABLE 1. The different phenotypes and roles of the valvular interstitial cells (VICs)

\begin{tabular}{|c|c|c|c|}
\hline Cell type & Role & Location & Ref. \\
\hline $\begin{array}{l}\text { Embryonic } \\
\text { endothelial } \\
\text { progenitor cells } \\
\text { (EPCs)/ } \\
\text { mesenchymal } \\
\text { stem cells } \\
\text { (MSCs) }\end{array}$ & $\begin{array}{c}\text {-Precursors of VICs that can be localized during } \\
\text { valve development. } \\
\text { - During endothelial-to-mesenchymal transformation } \\
\text { stage, those precursors, move from the endothelial } \\
\text { layer invading the cardiac jelly of the endothelial } \\
\text { cushion where they proliferate and differentiate into } \\
\text { VICs. }\end{array}$ & Migrating & (22) \\
\hline $\begin{array}{c}\text { Quiescent } \\
\text { valvular } \\
\text { interstitial cells } \\
\text { (qVICs) }\end{array}$ & $\begin{array}{l}\text { - Maintenance of heart valve structure and its } \\
\text { functions. } \\
\text { - Regulation of extracellular matrix (ECM) related } \\
\text { processes. } \\
\text { - Inhibition of angiogenesis. }\end{array}$ & $\begin{array}{c}\text { In the } 3 \\
\text { layers }\end{array}$ & (207) \\
\hline $\begin{array}{c}\text { Activated } \\
\text { valvular } \\
\text { interstitial cells } \\
\text { (aVICs) }\end{array}$ & $\begin{array}{l}\text { - After damage, aVICs increase the number stress } \\
\text { fibres and } \alpha \text {-SMA expression, transforming them into } \\
\text { VICs. } \\
\text { - Increase cytokine secretion and ECM remodelling. } \\
\text { - Once the process is achieved aVICs are removed via } \\
\text { apoptosis. } \\
\text { - Failures in the process result in pathological states. } \\
\text { - Therapeutic targets. }\end{array}$ & $\begin{array}{l}\text { In the } 3 \\
\text { layers }\end{array}$ & $(24,25)$ \\
\hline $\begin{array}{l}\text { Progenitor } \\
\text { valvular } \\
\text { interstitial cells } \\
\quad(\mathrm{pVICs})\end{array}$ & $\begin{array}{c}\text { - pVICs express endothelial and mesenchymal } \\
\text { markers. } \\
\text { - Circulating progenitors from bone marrow. } \\
\text { - Capable of differentiating towards aVICs directly or } \\
\text { via a qVIC step. }\end{array}$ & Circulating & $(26,27,28)$ \\
\hline $\begin{array}{l}\text { Osteoblastic } \\
\text { valvular } \\
\text { interstitial cells } \\
\text { (obVICs) }\end{array}$ & $\begin{array}{l}\text { - Promote calcification. } \\
\text { - obVICs control the deposition of ECM that is } \\
\text { responsible for heart valve calcification in } \\
\text { pathological processes. }\end{array}$ & Unknown & (29) \\
\hline
\end{tabular}




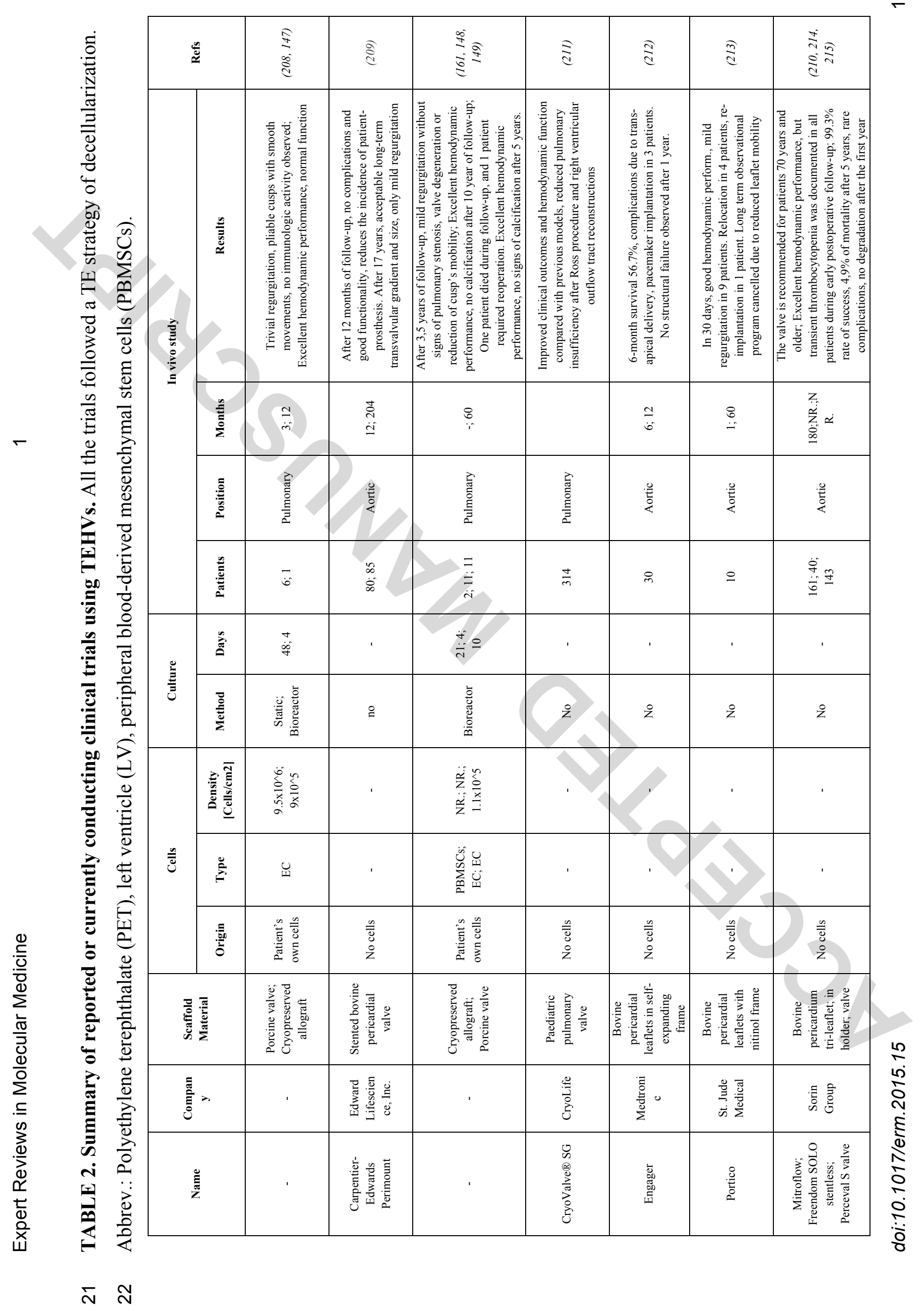




\begin{tabular}{|c|c|c|c|}
\hline$\stackrel{0}{2}$ & $\begin{array}{l}2 \\
\text { à } \\
\frac{2}{8}\end{array}$ & $\begin{array}{l}\hat{\sigma} \\
\infty \\
\text { do }\end{array}$ & $\stackrel{\bar{a}}{\mathrm{~d}}$ \\
\hline 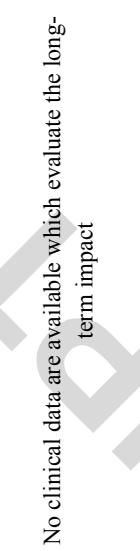 & 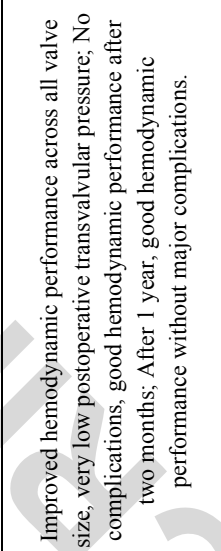 & 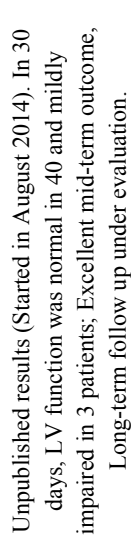 & 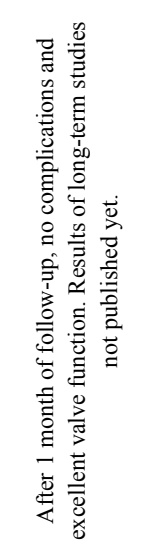 \\
\hline 8 & $\begin{array}{l}\tilde{z}_{\tilde{z}} \\
\tilde{z}\end{array}$ & $\begin{array}{l}\stackrel{4}{4} \\
\text { i } \\
\end{array}$ & 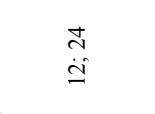 \\
\hline 参 & 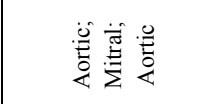 & & \\
\hline ্ֻণ & $\begin{array}{l}\ddot{i} \\
\ddot{i} \\
\ddot{n}\end{array}$ & $\overrightarrow{\ddot{q}}$ & \\
\hline$\stackrel{\gtrless}{z}$ & $\stackrel{8}{z}$ & $\stackrel{2}{z}$ & $\stackrel{2}{z}$ \\
\hline ' & , & , & , \\
\hline ' & ' & ' & , \\
\hline $\begin{array}{l}\frac{n}{\bar{E}} \\
\stackrel{0}{g}\end{array}$ & $\begin{array}{l}\frac{n}{\bar{E}} \\
\stackrel{0}{z} \\
\check{z}\end{array}$ & $\begin{array}{l}\frac{n}{\bar{E}} \\
\stackrel{0}{z}\end{array}$ & $\begin{array}{l}\frac{n}{\bar{E}} \\
0 \\
\check{z}\end{array}$ \\
\hline 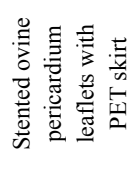 & 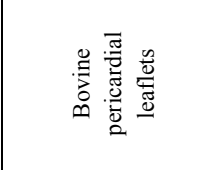 & 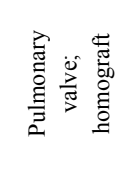 & 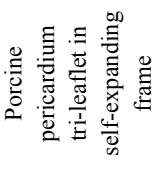 \\
\hline 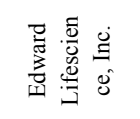 & 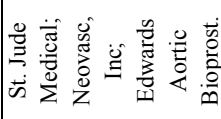 & بَّ & 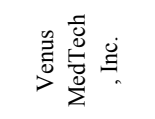 \\
\hline 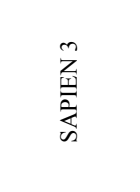 & 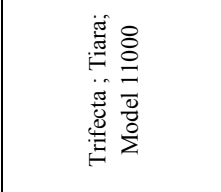 & 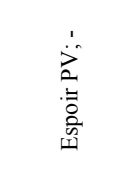 & 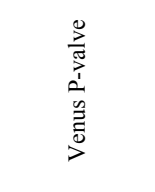 \\
\hline
\end{tabular}




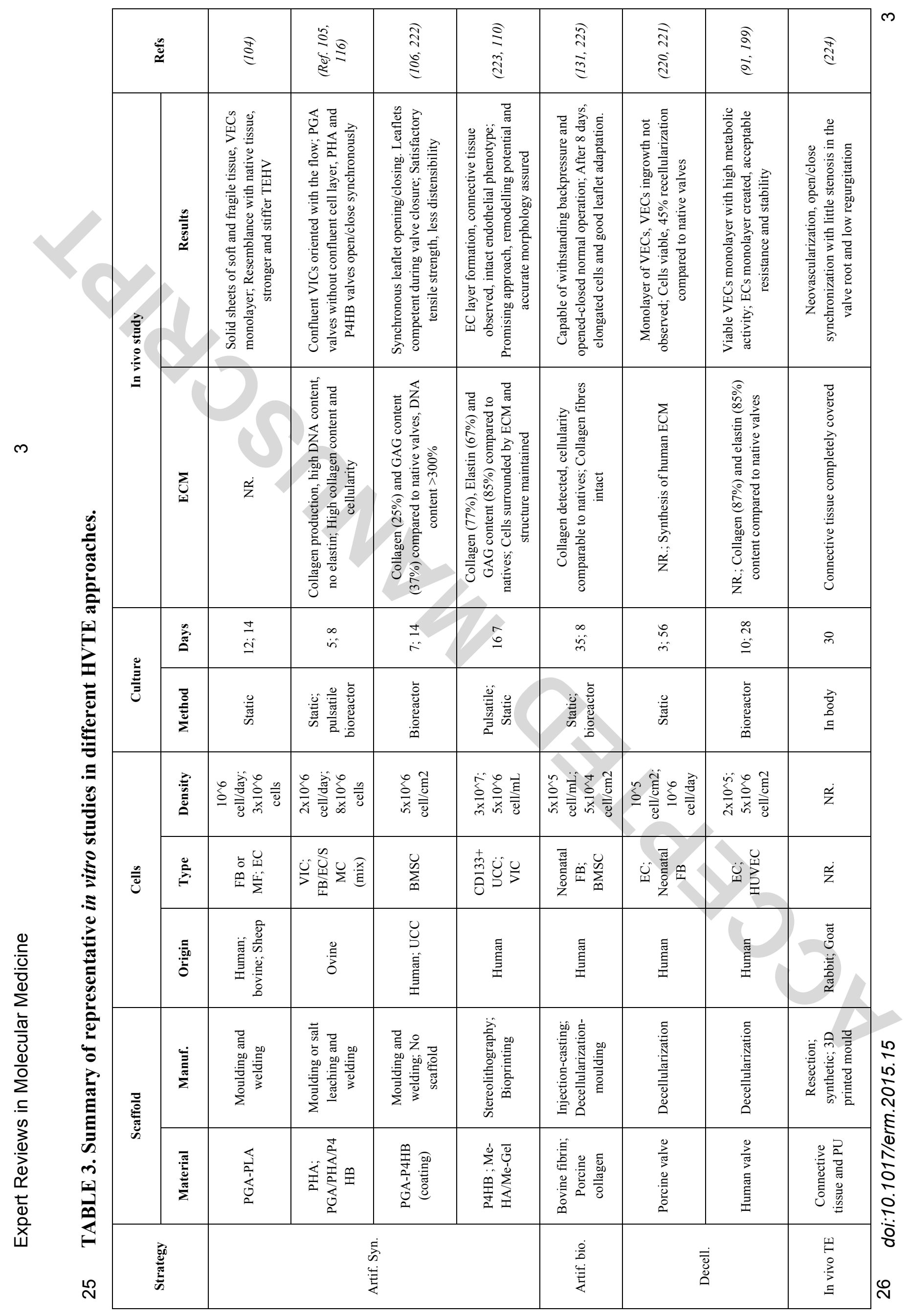




\begin{tabular}{|c|c|c|c|c|c|c|c|c|c|c|}
\hline & & & & 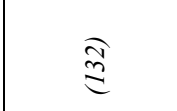 & 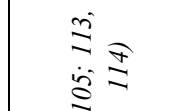 & 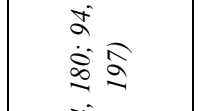 & $\begin{array}{l}\stackrel{\pi}{2} \\
\stackrel{0}{\infty}\end{array}$ & $\stackrel{\mathbb{d}}{\widehat{\mathbb{d}}}$ & $\stackrel{a}{d}$ & 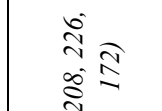 \\
\hline & & & $\frac{n}{\bar{z}}$ & 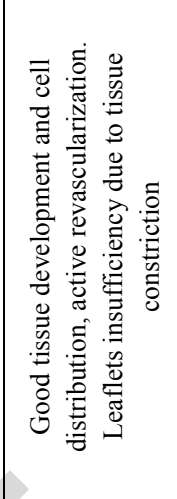 & 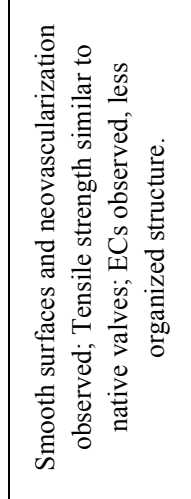 & 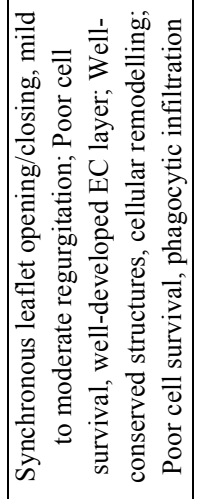 & 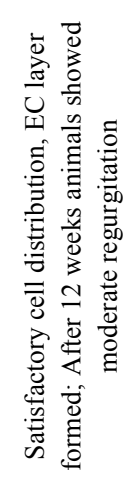 & 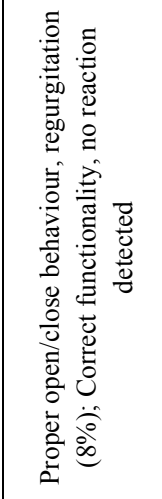 & 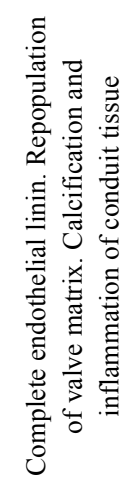 & 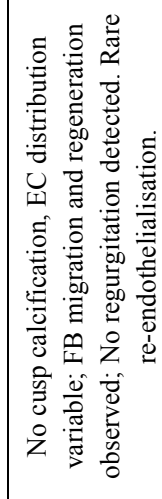 \\
\hline$\nabla$ & & 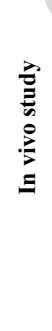 & 竞 & 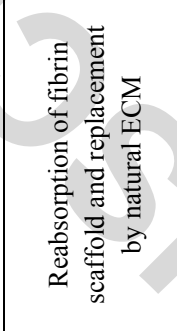 & 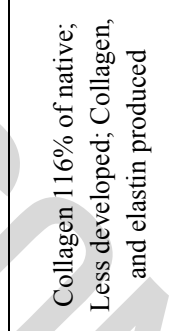 & 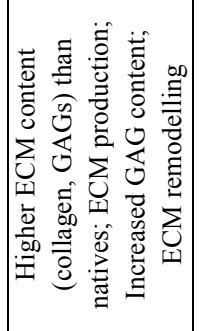 & 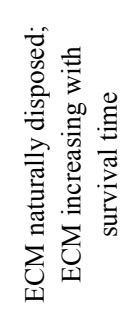 & 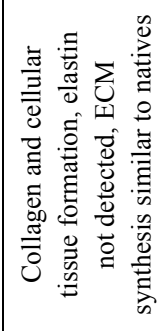 & 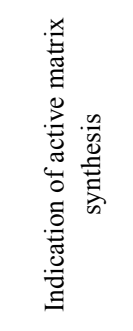 & 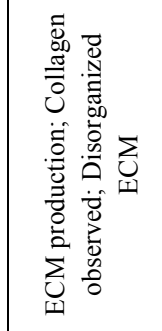 \\
\hline & $\dot{\mathscr{\varphi}}$ & & $\frac{9}{8}$ & $\simeq$ & & & $\begin{array}{l}\stackrel{i}{1} \\
\ddot{m}\end{array}$ & $\underset{\dot{\infty}}{+}$ & $\simeq$ & $\begin{array}{l}\ddot{\vec{N}} \bullet \\
\ddot{\underline{I}}\end{array}$ \\
\hline & 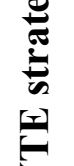 & & 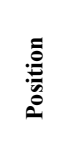 & 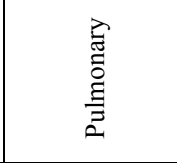 & 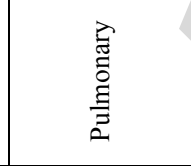 & & 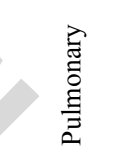 & 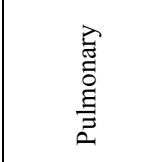 & 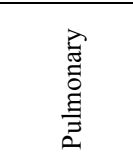 & $\begin{array}{l}\text { 焉 } \\
\text { 总 } \\
\text { 言 }\end{array}$ \\
\hline & 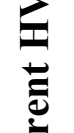 & & $\frac{\bar{\Xi}}{\bar{z}}$ & 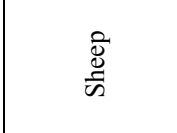 & हี & $\begin{array}{l}\ddot{\hat{0}} \\
\text { 芯 } \\
\text { 芯 }\end{array}$ & & & हี & $\frac{\mathscr{\Xi}}{\tilde{n}}$ \\
\hline & $\stackrel{\square}{0}$ & & 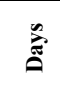 & $\stackrel{\infty}{\sim}$ & $\stackrel{\Xi}{\ddot{q}}$ & $\stackrel{0}{0}$ & $\stackrel{\infty}{\sim}$ & & $\ddot{6}$ & $\ddot{\ddot{r}} 0$ \\
\hline & 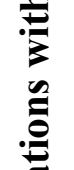 & 童 & 总 & 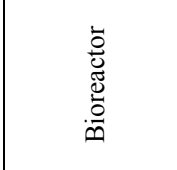 & 惫 & 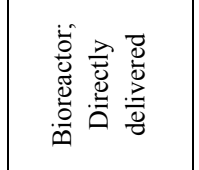 & 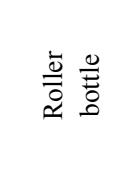 & & & 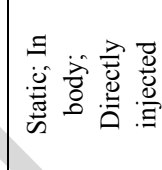 \\
\hline & $\sum_{0}^{000}$ & & 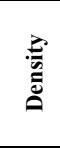 & 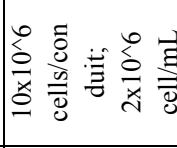 & 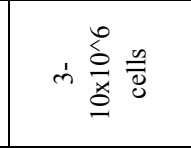 & 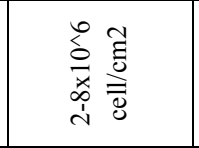 & 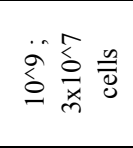 & 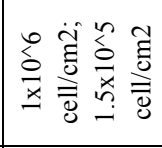 & & 岁 \\
\hline$\frac{9}{10}$ & . & $\frac{\varrho}{\overline{\bar{U}}}$ & $\stackrel{g}{E}$ & 巃㞻 & 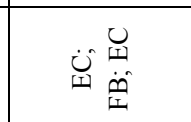 & 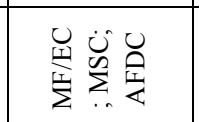 & $\sum_{m}^{u}$ & 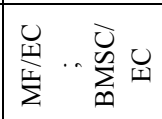 & 峷总 & $\because \sum_{i} \sum_{m}$ \\
\hline$\frac{2}{\overline{0}}$ & $\frac{d}{d}$ & & $\frac{\bar{y}}{\bar{\partial}}$ & $\stackrel{0}{5}$ & $\stackrel{\mathscr{g}}{\sigma}$ & 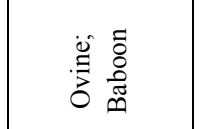 & $\stackrel{\mathscr{g}}{\sigma}$ & है & $\frac{\mathscr{g}}{\partial}$ & $\stackrel{\mathscr{\xi}}{\partial}$ \\
\hline 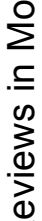 & 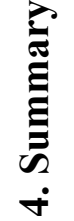 & 䒿 & 訔 & 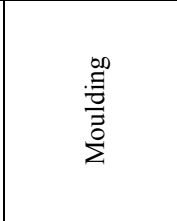 & 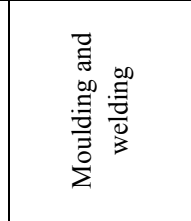 & 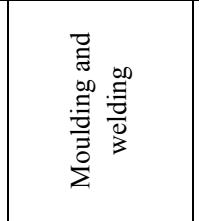 & 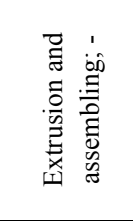 & 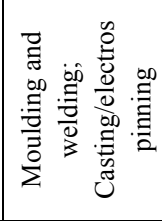 & 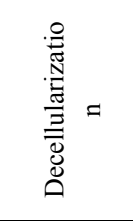 & 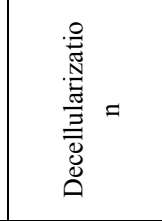 \\
\hline 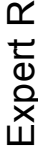 & 我 & $\infty$ & 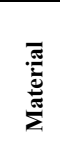 & 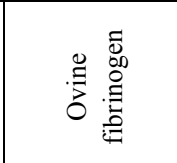 & 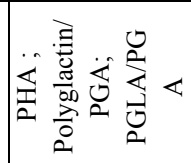 & 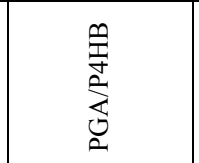 & 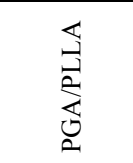 & 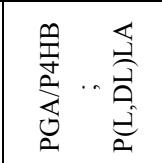 & 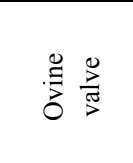 & 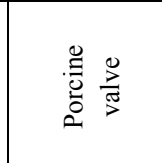 \\
\hline & $\hat{\sim}$ & & & 岁 & & & & & & \\
\hline
\end{tabular}

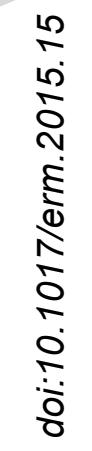




\begin{tabular}{|c|c|c|}
\hline \multirow{8}{*}{ م } & 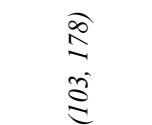 & $\stackrel{\text { dิ }}{d}$ \\
\hline & 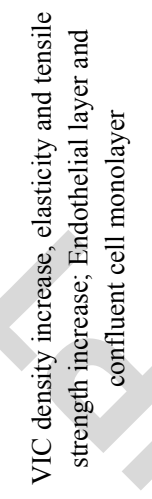 & 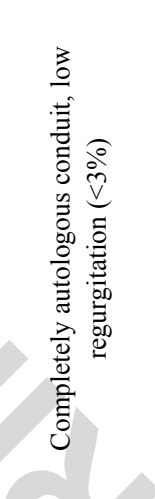 \\
\hline & 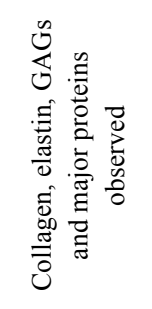 & 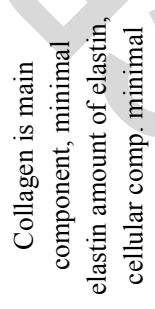 \\
\hline & $\simeq$ & - \\
\hline & $\begin{array}{l}\text { 焉 } \\
\text { 言 } \\
\text { 吾 }\end{array}$ & 离. \\
\hline & 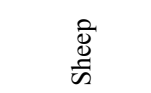 & 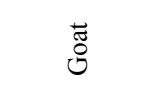 \\
\hline & $\stackrel{0}{\dddot{\sim}}$ & 8 \\
\hline & 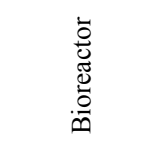 & $\begin{array}{l}\text { 帘 } \\
0 \\
\Xi \\
\Xi\end{array}$ \\
\hline \multirow{6}{*}{ 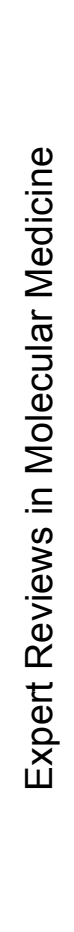 } & 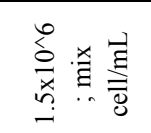 & 亗 \\
\hline & 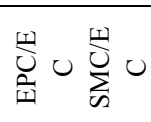 & \\
\hline & $\frac{\mathscr{\sigma}}{\sigma}$ & 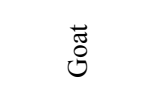 \\
\hline & 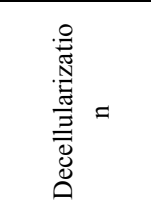 & 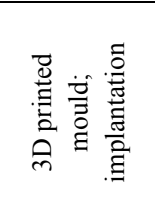 \\
\hline & 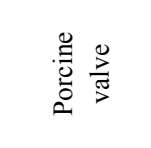 & 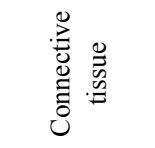 \\
\hline & & $\stackrel{D}{I}_{\Xi}^{D}$ \\
\hline
\end{tabular}

